\title{
Grid-Connected Control of Wind Turbine with Differential Speed Regulation Based on Fuzzy Decision Makings
}

\author{
Xiaoming Rui ${ }^{1}$, Lubing Xie ${ }^{1}$, Xiaochao Fan ${ }^{2} \&$ Changkai Xiu ${ }^{1}$ \\ ${ }^{1}$ School of Energy Power and Mechanical Engineering, North China Electric Power University, Beijing 102206, \\ China \\ ${ }^{2}$ College of Electrical Engineering, Xinjiang University, Yanan Road, Tianshan District, Urumqi, 830000, China \\ Correspondence: Lubing Xie, School of Energy Power and Mechanical Engineering, North China Electric Power \\ University, Beijing 102206, China. E-mail: Xie_Lubing@126.Com
}

Received: August 2, 2019

Accepted: August 21, 2019

Online Published: August 22, 2019

Doi:10.5539/Mas.V13n9p10

URL: Https://Doi.Org/10.5539/Mas.V13n9p10

\begin{abstract}
To solve the problem of grid-connected control of differential speed-regulating wind turbines, the wind turbine, transmission chain, speed-regulating motor, and generator model of the unit are constructed using the MATLAB/Simulink platform. The differential speed-regulating control system is designed on the basis of slip-frequency and fuzzy control theories. The speed control function and characteristics on maximum power tracing of wind turbine is tested via simulation. Meanwhile, the experimental bench for the differential speed-regulating wind power system is set up. Test results indicate that the generator speed is controlled by speed-regulating motor with output voltage and frequency that are approximately synchronized with those of power grid under idle load condition. The maximum wind-power utilization coefficient is maintained by fuzzy controller under the rated wind speed. Thus, the accuracy and efficiency of the designed control system is proven and provide important implications for further investigations on the grid-connected control of wind turbines with differential speed regulation.
\end{abstract}

Keywords: grid-connected control, strategy, simulation, wind turbine, differential speed regulation

\section{Introduction}

In recent years, China's wind power industry has maintained a steady development trend. By the end of 2018, the installed capacity of grid-connected wind power in China has reached 184 million $\mathrm{kW}$, the total hoisting capacity of wind power accounts for $9.7 \%$ of the total installed capacity of power in China, and wind power generation accounts for $5.3 \%$ of the total social power generation. Variable-speed constant-frequency wind turbine has been widely used with the rapid development of wind power in China due to its economy and good tracking and utilization ability of wind energy. With China's wind power industry gradually entering the stage of large capacity development, Variable-speed constant-frequency technology has been greatly upgraded and developed. However, the technical limitations of the power output control of generators are gradually emerging. The increasing capacity of single-machine systems has made the power matching of the core component converter a technical difficulty (Sainz, L., Monjo, L., Pedra, J., et al., 2017)(Huang, L., Xin, H., Zhang, L., 2017).

Scholars have carried out relevant research on differential speed-regulating wind power systems. Early research has focused on the design principle of differential speed regulation. For example, Mangialard et al. (Mangialardi, L., Mantriota, G., 1999) comprehensively discussed the principle and feasibility of differential speed regulation by simulating a differential speed-regulating wind power system but did not include the design of a speed-regulating control system. Idan et al. proposed a transmission design scheme using a two-stage planetary gear transmission system and proposed a robust control solution based on the maximum power output of wind turbines (Idan, M., Lior, D.,, 2000). Zhao et al. (Zhao, X., Mai, E. P., 2003) proposed a system design concept similar to the power dividing transmission chain and unified the subsystem models into the electromechanical dynamics model of wind power generation system. Li ( $\mathrm{Li}, \mathrm{L} ., 2010)$ studied a transmission scheme that combines high mechanical transmission with hydraulic speed regulation on the basis of the mechanism and technical feasibility analyses of the power-dividing speed-regulating transmission scheme. Rui et al. (Rui, X., Su, R., Wu, X., et al., 2014) proposed a conceptual design of grid-connected wind turbine based on differential speed-regulating mechanism to determine the fault information of grid-connected wind turbine converter. Early grid-connected wind turbines have 
mainly adopted fixed-pitch constant-speed control mode, which has been gradually replaced by the doubly-fed and direct-drive permanent magnet variable-speed and constant-frequency technology. In recent years, the technical limitations of variable-speed and constant-frequency technology in grid-connected speed control have attracted the attention of scholars in the industry. Wu et al. (Wu, X., Su, R., Rui, X., 2014) proposed a design scheme of hydraulic-mechanical variable-speed transmission system for grid-connected wind turbines. Without a speed-up gearbox and a frequency converter, the generator can output power to the grid at a constant frequency. Jelaska et al. (Jelaska, D., Podrug, S., Perku, I. M., 2015) proposed a novel power synthesis hybrid transmission that can convert the wind turbine speed to the constant speed of the generator spindle. Krupke et al. (Krupke, C., Wang, J., Clarke, J. et al., 2017) introduced a new power distribution device by continuously variable transmission connection of the turbine drive shaft with an air compressor. The stable power output of hybrid wind turbine system under wind speed fluctuation was obtained through the analysis and testing of the generator system. While studying the optimization and upgrading of variable speed costant frequency technology, scholars have also researched on differential speed-regulating systems. Wu (Wu, X., Su, R., Rui, X., Lu, C., 2015) established a three-axis dynamic model with a spring-damper-mass system through simulation using Simulink software to study the dynamic characteristics of differential speed-governing wind turbines. With the step wind load as the input of the model, the rotational speed, torque, and power of the differential gear train's frame, gear ring, and solar wheel shafts were obtained, and the frequency distribution of the torque signal was further derived. Su et al. (Su, R., Yang, Q., Liu, P., Li, H., Huang, Y., Wang, J., 2019) established a pure torsion time-varying nonlinear dynamic model of wind turbine drive system with differential speed regulation based on a dynamic meshing equation that considers time-varying meshing stiffness, backlash, and damping and analyzed the frequency distribution of the dynamic meshing curve. The feasibility of the transmission principle of differential-speed control wind turbine was verified by analyzing the test data of the speed regulation and the power coupling characteristics of the key components to validate the transmission principle of the differential-speed control wind turbine ( $\mathrm{Su}, \mathrm{R} ., \mathrm{Liu}, \mathrm{P}$., Li, H., Huang, Y., Wang, J., 2018)(Ye, H, 2015)(Tang, X, Yin, M., 2016)(Li, S. Zhu, G., 2017)(Ran, B., Cheng, Z., Donald M.H., 2017)(Zhang, X.Y., 2014)(Clemens, H., Wout, W., 2019). The literature review reveals that the research on differential wind turbines in recent years has mainly focused on the correlation analysis of dynamic characteristics, while the research on operation characteristic simulation and control system grid-connected testing is relatively limited.

On the basis of the charThe primary goal of this paper is to carry out the operation characteristics of differential speed-regulating wind turbine, simulates modeling of control system and grid-connected control, and conducts test panel verification on the basis of the characteristics of the $2 \mathrm{~K}-\mathrm{H}$ differential speed-regulating wind turbine with two degrees of freedom.. This paper were arranged as follows. First, the model of wind wheel, transmission chain, speed-regulating motor, and generator is constructed for differential speed-regulating wind turbine by using the MATLAB/Simulink platform. Simulation experiments of the unit components and the entire unit are performed, and the basic operation characteristics are obtained. Second, design of fuzzy controller using fuzzy control method, fuzzy output, and clarification process are deduced on the basis of fuzzy control rules and through the analysis of the characteristics of differential speed-regulating wind turbine to achieve maximum power tracking under rated wind speed. The corresponding control rules and the simulation model of fuzzy controller for differential-speed control wind power system are established using the Simulink simulation platform. Finally, the physical test panel of differential speed-regulating wind power system is built and the preliminary operation test analysis of generator and speed-regulating motor in no-load grid-connected process is carried out to verify the stability of the output voltage of the generator system. The test results show that the output voltage and frequency of the generator are the same as those of the power grid in the no-load grid-connected stage. Fuzzy control can keep the maximum wind energy utilization coefficient of the unit under the rated wind speed. The experimental results verify the effectiveness of the designed control system. 


\section{Simulation Modeling and Test Bench Design of Differential Speed-Regulating Wind Power System}

\subsection{Simulation Modeling}

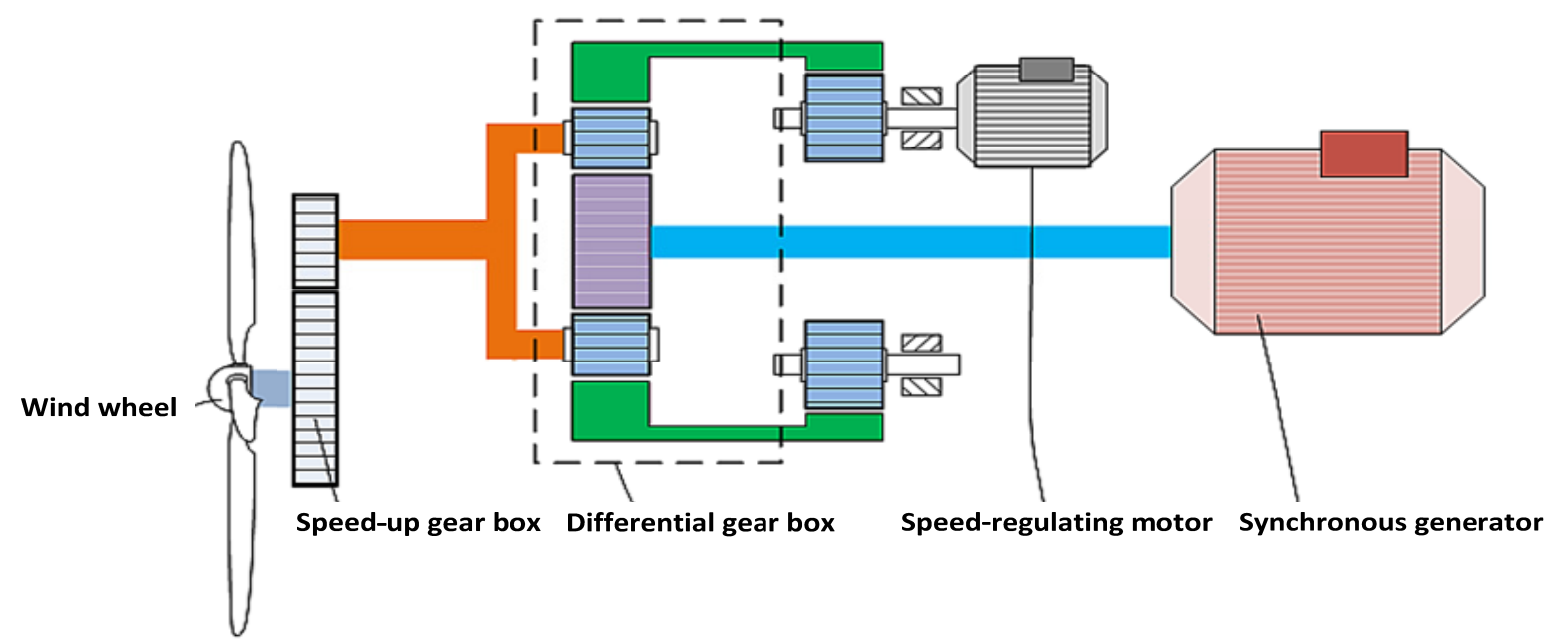

Figure 1a. Structural Diagram of Differential Speed Regulation System

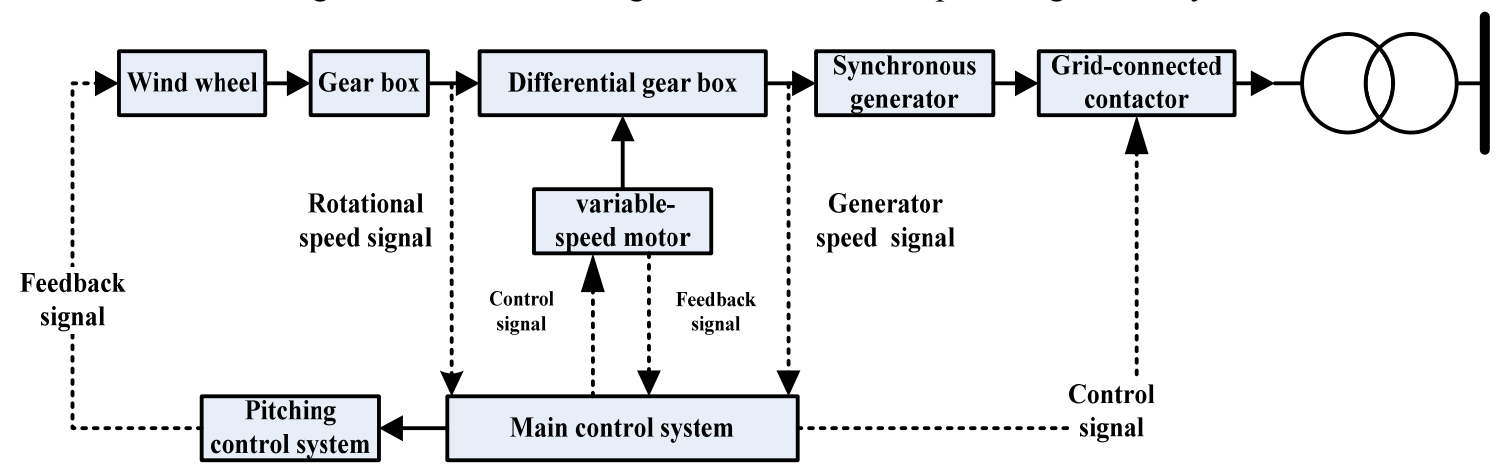

Figure 1b. Control System of Wind Turbine with Differential Speed Regulation

A differential speed-regulating wind turbine is mainly composed of a wind wheel, a speed-up gear box, a $2 \mathrm{~K}-\mathrm{H}$ differential gear box, a synchronous generator, and an asynchronous speed-regulating motor (See Figure 1. a ). Previous simulation studies on wind turbine control systems have mainly focused on constant- or variable-speed and constant-frequency wind turbines. The structure and operation mode of the differential speed-regulating wind turbine studied in this work are quite different from those in previous studies. Therefore, the key components of the wind turbine should be modeled. The control system of wind turbine with differential speed regulation are shown in Figure 1. b. The main Simulink modules used in this study include Sim-Power-System, Gears, and Fuzzy Control Toolbox. The reference data of modeling are shown in Table 1. The specific situation of each model construction and the corresponding simulation results are summarized as follows. 
Table 1. Parameters of a 1.5 MW Wind Power Unit

\begin{tabular}{cccc} 
Name & $\begin{array}{c}\text { Reference } \\
\text { value }\end{array}$ & Name & Reference value \\
\hline Wind wheel radius & $41 \mathrm{~m}$ & Running speed of wind turbine & $6-18 \mathrm{r} / \mathrm{min}$ \\
Rated power & $1500 \mathrm{~kW}$ & Generator type & $\begin{array}{c}\text { Synchronous } \\
\text { generator }\end{array}$ \\
Cut in wind speed & $3 \mathrm{~m} / \mathrm{s}$ & Generator rated voltage & $690 \mathrm{~V}$ \\
$\begin{array}{c}\text { Cut off wind speed } \\
\text { Rated wind speed }\end{array}$ & $25 \mathrm{~m} / \mathrm{s}$ & Rated speed of generator & $1500 \mathrm{r} / \mathrm{min}$ \\
$\begin{array}{c}\text { Optimum tip speed ratio } \\
\text { Maximum wind energy } \\
\text { utilization Coefficient }\end{array}$ & 0.44 & Generator pole logarithm & 2 \\
$\begin{array}{c}\text { Speed-up gear box } \\
\text { transmission ratio }\end{array}$ & 30 & Variable-speed motor types & Asynchronous \\
motor \\
$\begin{array}{c}\text { Structural parameters of } \\
\text { differential gearbox }\end{array}$
\end{tabular}

\subsubsection{Wind Speed Model}

The combined wind speed model is selected as the wind speed input of wind power control system in reflecting the changing characteristics of natural wind speed. The formula of the combined wind speed model is expressed as follows.

$$
v_{w}=\bar{v}+v_{g}+v_{c}+v_{n}
$$

$\bar{v}$ is the basic component of wind speed and has a constant value, unit $(\mathrm{m} / \mathrm{s}) ; v_{g}$ is the gust component; $v_{c}$ is a gradient wind component; and $v_{n}$ is a random wind component. The wind speed model is verified and modeled in MATLAB/Simulink. The basic wind speed is set to $7 \mathrm{~m} / \mathrm{s}$, the gust time is $10-35 \mathrm{~s}$, and the simulation time is $50 \mathrm{~s}$. The simulation results are shown in Figure 2. The results show that the wind speed model can reflect the characteristics of natural wind speed effectively.

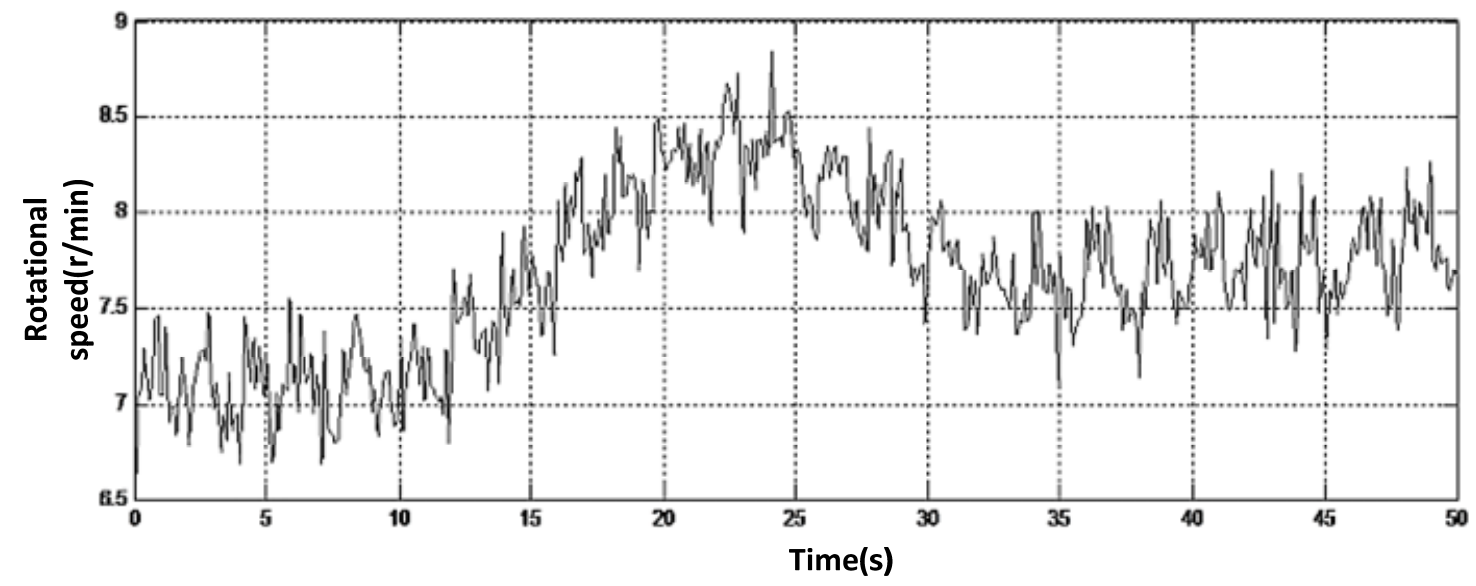

Figure 2. Effect of Wind Speed Model 




\subsubsection{Wind Turbine Model}

Figure 3. Composed Wind Speed Simulink Model

(1) Wind Energy Utilization Coefficient: Wind wheel is the component of wind turbine that captures wind energy and is also the main power input component of the transmission chain. Wind energy utilization coefficient is the main parameter to characterize wind turbines and is related to the geometric parameters of wind turbines and the tip speed ratio. The relationship curve between wind energy utilization coefficient and tip speed ratio is fitted by MATLAB in accordance with a set of data of wind energy utilization coefficient and tip speed ratio shown in Table 2 to accurately describe the characteristics of wind turbine. Fitting function is used to describe the wind energy utilization characteristics of generating units and determine the relevant parameters of the simulation model.

Table 2. Wind Energy Utilization Coefficient Corresponding to Tip Speed Ratio

\begin{tabular}{llllllllll}
\hline $\begin{array}{l}\text { Tip speed ratio } \lambda \\
\text { Wind energy }\end{array}$ & 0 & 2 & 4 & 6 & 8 & 10 & 12 & 14 & 16 \\
\begin{tabular}{l} 
coefficient $C p$ \\
\hline
\end{tabular} & 0 & 0.05 & 0.17 & 0.31 & 0.44 & 0.41 & 0.35 & 0.22 & 0 \\
\hline
\end{tabular}

Let $f(x)=P_{1} X^{4}+P_{2} X^{3}+P_{3} X^{2}+P_{4} X+P_{5}$ be the polynomial expression of the fitting function. On the basis of the data in Table 2, the relationship curve between wind energy utilization coefficient $C_{P}$ and tip velocity ratio $\lambda$ is fitted by MATLAB. Notably, $P_{1}=6.192 \times 10^{-5}, P_{2}=-0.00244, P_{3}=0.0243, P_{4}=-0.01662$, and $P_{5}=0.0009479$. The fitting curve is shown in Figure 4. When the tip speed ratio is 8, the maximum wind energy utilization coefficient is 0.44 .

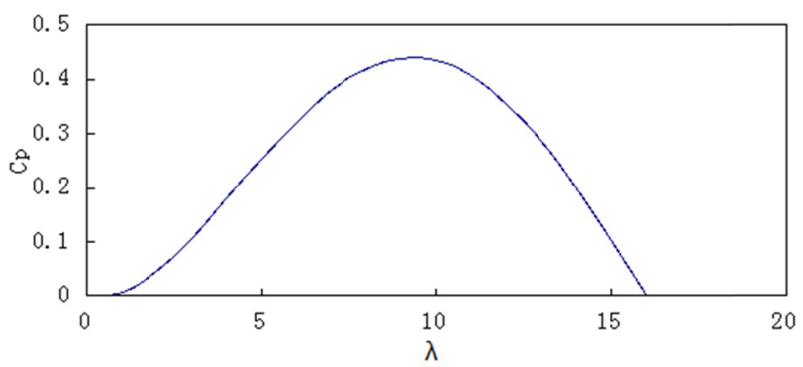

Figure 4. Wind Energy Utilization Coefficient Curve of Unit Characteristics

Wind Turbine Theory Analysis and Modeling: When the rated wind speed of variable-speed wind turbine is high, the pitch angle of blades should be adjusted to control the wind turbine for absorbing wind energy. In this case, $C_{p}=f(\lambda, \beta)$. The approximate expression of the function can be expressed as 


$$
\left\{\begin{array}{l}
C_{p}(\lambda, \beta)=0.22\left(\frac{116}{\lambda_{i}}-0.4 \beta-5\right) e^{\frac{-12.5}{\lambda_{i}}} \\
\frac{1}{\lambda_{i}}=\frac{1}{\lambda-0.08 \beta}-\frac{0.035}{\beta^{3}+1}
\end{array}\right.
$$

In Formula (2), $\lambda$ is the tip velocity ratio and $\beta$ is the pitch angle.

At rated wind speed, the maximum power of the unit is not reached. Therefore, maximum power tracking is controlled in this stage. Specifically, the pitch angle of differential speed-regulating wind turbines is always zero when the wind speed is below the rated speed. The maximum wind energy utilization factor $C_{P}=f(\lambda)$ is below the rated wind speed. When the utilization coefficient of wind energy is known, the power of the wind turbine can be obtained. Then, the wind turbine torque can be obtained. From the above-mentioned calculation logic, the Simulink simulation model of wind turbine can be established.

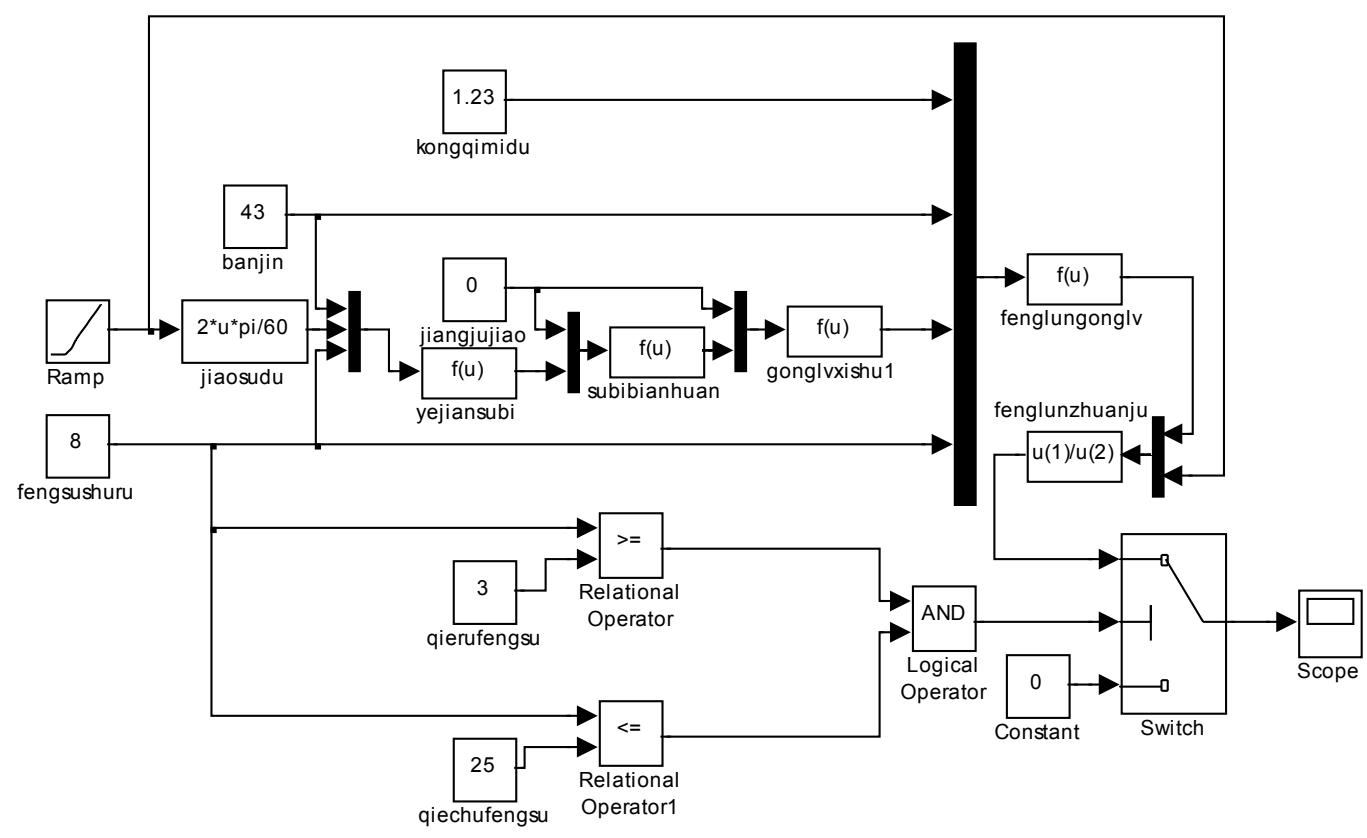

\subsubsection{Drive Chain Model}

Figure 5. Wind Wheel Simulink Model

The transmission chain of wind turbine determines the motion relationship among wind turbine, generator, and speed-regulating motor. The differential speed-regulating wind turbine adopts the $2 \mathrm{~K}-\mathrm{H}$ differential gear train to realize speed regulation. To study the transmission chain characteristics of differential speed-regulating wind turbines, the movement relationship of each component of the $2 \mathrm{~K}-\mathrm{H}$ differential gear train, the power interval of the speed-regulating motor, and the three-mass model of the transmission chain are analyzed theoretically. Finally, the simulation model is established.

\subsubsection{Kinematics Analysis of 2K-H Differential Gear Train}






Figure 6. Sketch of 2K-H differential gear train

\section{a: Sun Wheel, b: Gear Ring, c: Planet Carrier, g: Planet Gear}

The $2 \mathrm{~K}-\mathrm{H}$ differential gear train is a planetary gear train and is widely used in transmission systems. Its basic components include a central wheel, a planetary frame, and a gear ring. In addition to the conventional characteristics of the planetary gear train, it also has two degrees of freedom of motion, which can be used as a mechanism for synthesizing and decomposing speed. The structural diagram of the differential gear box is shown in Figure 6. Figure 6 shows that the planetary gear is meshed with the solar wheel and the gear ring. If the solar wheel is not rotated, then the bogie of the planetary gear is the same as that of the gear ring; if the gear ring is not rotated, then the rotation of the planetary gear is opposite that of the solar wheel. Relative velocity method is used to analyze the relationship between the rotational speed and transmission ratio of solar wheel, gear ring, and planetary frame of $2 \mathrm{~K}-\mathrm{H}$ differential gear train components. When the number of teeth of the sun gear and the number of teeth of the ring gear or the rotational speed of the planetary frame and the rotational speed of the ring gear are determined, the rotational speed of the third axis can be calculated. Differential speed-regulating wind turbines utilize this characteristic of differential gearbox to obtain constant speed of generator.

\subsubsection{Power Interval Analysis of Speed-Regulating Motor}

The $2 \mathrm{~K}-\mathrm{H}$ differential gear train is a unit of power transmission. Its power transmission form can be any two axes as the power input and one axle as the power output. It can also be any two axes as the power output end and one axle as the power input end. The power relationships of the three axes satisfy the following formula regardless of the transmission mode and the energy loss, such as frictional resistance.

$$
P_{R}+P_{S}+P_{C}=0
$$

In the formula, $P_{R}, P_{S}$, and $P_{c}$ are the powers of planetary frame, solar wheel, and gear ring axle ends, respectively. According to Formulas (3) and (4).

$$
\begin{gathered}
P=T \cdot \omega \\
T_{b} \omega_{b}+T_{h} \omega_{h}+T_{a} \omega_{a}=0
\end{gathered}
$$

If the direction of the gear ring torque is positive when the planetary frame and the gear ring are used as the active parts, then

$$
T_{b}+T_{h}=T_{a}-T_{h}
$$

In Formulas (4), (5), and (6), $\mathrm{T}$ is the wind wheel torque; $\omega$ is the wind wheel angular velocity; and $T a$., $T b$, and $T h$ are the torques of solar wheel, gear ring, and planetary frame, respectively. $\omega a, \omega b$, and $\omega h$ is the angular velocities of solar wheel, gear ring, and planetary frame, respectively. After the speed-regulating motor is connected to the grid, the input power of the speed-regulating motor to the transmission chain changes with the adjustment of the speed of the wind wheel. Therefore, the reasonable power range of the speed-regulating motor should be determined reasonably. Given the speed of the wind wheel, the gear ring should play a regulating role to maintain the constant speed of the output of the solar wheel. The input power of the speed-regulating end should generally be less than that of the spindle end, that is, $P b / P h<1$. Therefore, the ideal working range of planetary gear train should be the A-B section in Figure 7, namely, $0.5(1+r)<n h / n s<1 /(1+r)$ and $-0.5 / r<n h / n s<0$. Among them, $r$ is the structural parameter of differential gearbox, which is equal to the ratio of the number of teeth of ring gear to the number of teeth of solar gear; $n h$ is the speed control motor; and $n s$ is the output speed of solar wheel. 


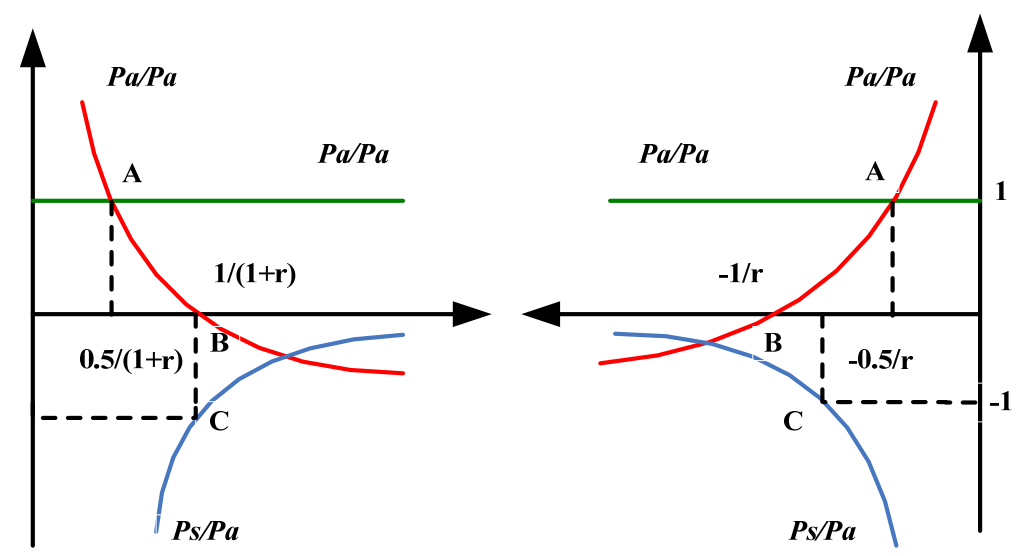

Figure 7. Relationship between Input Power Ratio of Gear Train Components and Planetary Frame

\subsubsection{Three-Mass Model of Transmission Chain}

For the transmission system of wind turbines, dynamic analysis is conducted using the lumped mass block model. The structural characteristics of differential speed-regulating wind turbine are also examined. Wind wheel and differential gear box low-speed shaft are regarded as the first mass block and spindle as the flexible shaft. Gear box high-speed shaft and generator rotor are regarded as the second mass block. Speed-regulating motor rotor and shaft are regarded as the third mass block for analyzing the transmission chain.

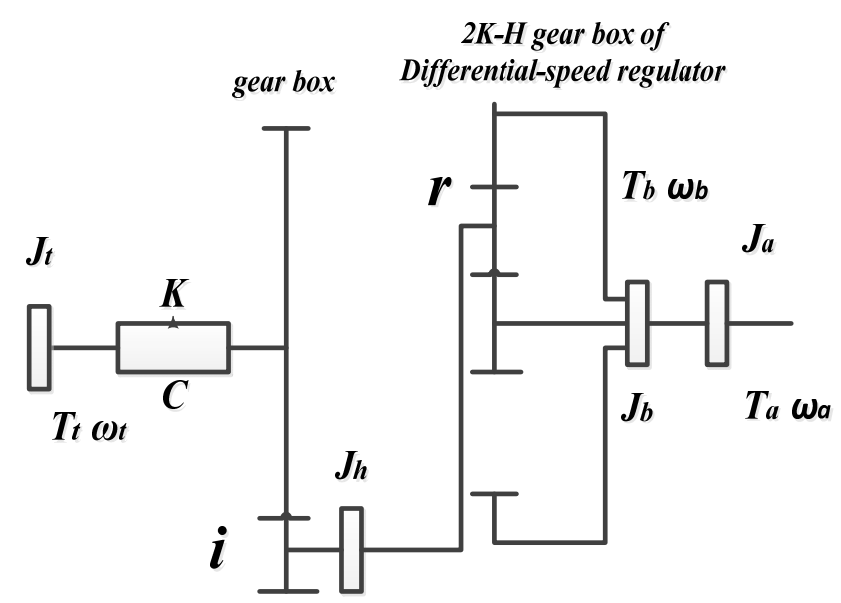

Figure 8. Three-Mass Modules of Gearing Chain

In Figure $8, \omega_{a}, \omega_{b}$, and $\omega_{t}$ are the speeds of solar wheel, gear ring, and wind wheel, respectively. $\mathrm{i}$ is the gearbox transmission ratio for speed increase. $J_{t}, J_{a}, J_{h}$, and $J_{b}$ are the rotational inertia of wind turbine, generator rotor, planetary frame, and gear ring, respectively. $\mathrm{C}$ is the spindle damping coefficient. $\mathrm{K}$ is the spindle stiffness coefficient. $r$ is the structural parameter of differential gear train.

The satisfaction formula of the relationship among the speeds of planetary frame, gear ring, wind wheel, and solar wheel is shown in Figure 8.

$$
\begin{gathered}
\omega_{a}=(1+r) \omega_{h}-r \omega_{b}=(1+r) i \omega_{t}-r \omega_{b} \\
r=\frac{Z_{b}}{Z_{a}}
\end{gathered}
$$

In the formula, $r$ is the structural parameter of differential gear train; $\omega_{a}, \omega_{b}, \omega_{h}$, and $\omega_{t}$ are the speeds of solar wheel, gear ring, planetary frame, and wind wheel, respectively; and $i$ is the transmission ratio of increasing gear box. The available planetary frame torque is expressed as follows.

$$
T_{h}=\frac{1}{i}\left[k \Delta \varphi_{h}+c\left(\omega_{t}-\frac{1}{i} \omega_{h}\right)\right]=\frac{k}{i} \Delta \varphi_{t}+\frac{c}{i} \omega_{t}-\frac{c}{i^{2}}\left[\frac{1}{1+r}\left(\omega_{a}-r \omega_{b}\right)\right]
$$




$$
\Delta \varphi_{t}=\int\left(\omega_{t}-\frac{\omega_{h}}{i}\right) d t=\int\left[\omega_{t}-\frac{1}{i(1+r)} \omega_{a}+\frac{r}{i(1+r)} \omega_{h}\right] d t
$$

The general equation of the system dynamics for speed and torque is as follows.

$$
J \frac{d \omega}{d t}=T_{m}-T_{\text {res }}
$$

In the formula, $J$ is the moment of inertia, $T_{m}$ is the external torque, and $T_{r e s}$ is the load torque. The relationship between the rotational speed and torque of planetary frame and gear ring is given as follows.

$$
\frac{r}{1+r} T_{h}=J_{b} \omega_{b}-T_{b}+\frac{r}{1+r} J_{h} \omega_{h}
$$

By substituting Formulas (7) and (9) into Formula (12), the following simplification can be obtained.

$$
J_{b} \omega_{b}+\frac{r}{(1+r)^{2}} J_{h}\left(\omega_{a}+r \omega_{b}\right)=\frac{r}{1+r}\left\{\frac{k}{i} \Delta \varphi_{t}+\frac{c}{i} \omega_{t}-\frac{c}{i^{2}}\left[\frac{1}{1+r}\left(\omega_{a}+r \omega_{b}\right)\right]\right\}+T_{b}
$$

The relationship between the rotational speed and torque of planetary frame and solar wheel is expressed as follows.

$$
\frac{1}{1+r} T_{h}=J_{a} \omega_{a}-T_{a}+\frac{1}{1+r} J_{h} \omega_{h}
$$

By substituting Formulas (7) and (9) into Formula (14), the following simplification can be obtained.

$$
J_{a} \omega_{a}+\frac{r}{(1+r)^{2}} J_{h}\left(\omega_{a}+r \omega_{b}\right)=\frac{r}{1+r}\left\{\frac{k}{i} \Delta \varphi_{t}+\frac{c}{i} \omega_{t}-\frac{c}{i^{2}}\left[\frac{1}{1+r}\left(\omega_{a}+r \omega_{b}\right)\right]\right\}
$$

If the spindle is a flexible shaft, then the relationship between torque and speed can be obtained as follows.

$$
\begin{gathered}
J_{t} \omega_{t}=T_{t}-k \Delta \varphi_{t}-c\left(\omega_{t}-\frac{\omega_{h}}{i}\right) \\
J_{t} \omega_{t}=T_{t}-k \Delta \varphi_{t}-c \omega_{t}+\frac{c}{i(1+r)} \omega_{a}+\frac{c r}{i(1+r)} \omega_{h}
\end{gathered}
$$

In the formula, $C$ is the spindle damping coefficient; $k$ is the spindle stiffness coefficient; $J t, J a, J h$, and $J b$ are the rotational inertia of wind turbine, generator rotor, planetary frame, and gear ring, respectively; $T a, T b, T h$, and $T t$ are the torques of solar wheel, gear ring, planetary frame, and wind wheel, respectively. From the above-mentioned theoretical analysis, the transmission chain simulation model of differential speed-regulating wind turbine can be established. On the basis of the analysis of the aforementioned theory, the transmission chain simulation model of the differential speed-regulating wind turbine is established, as shown in Figure 9.

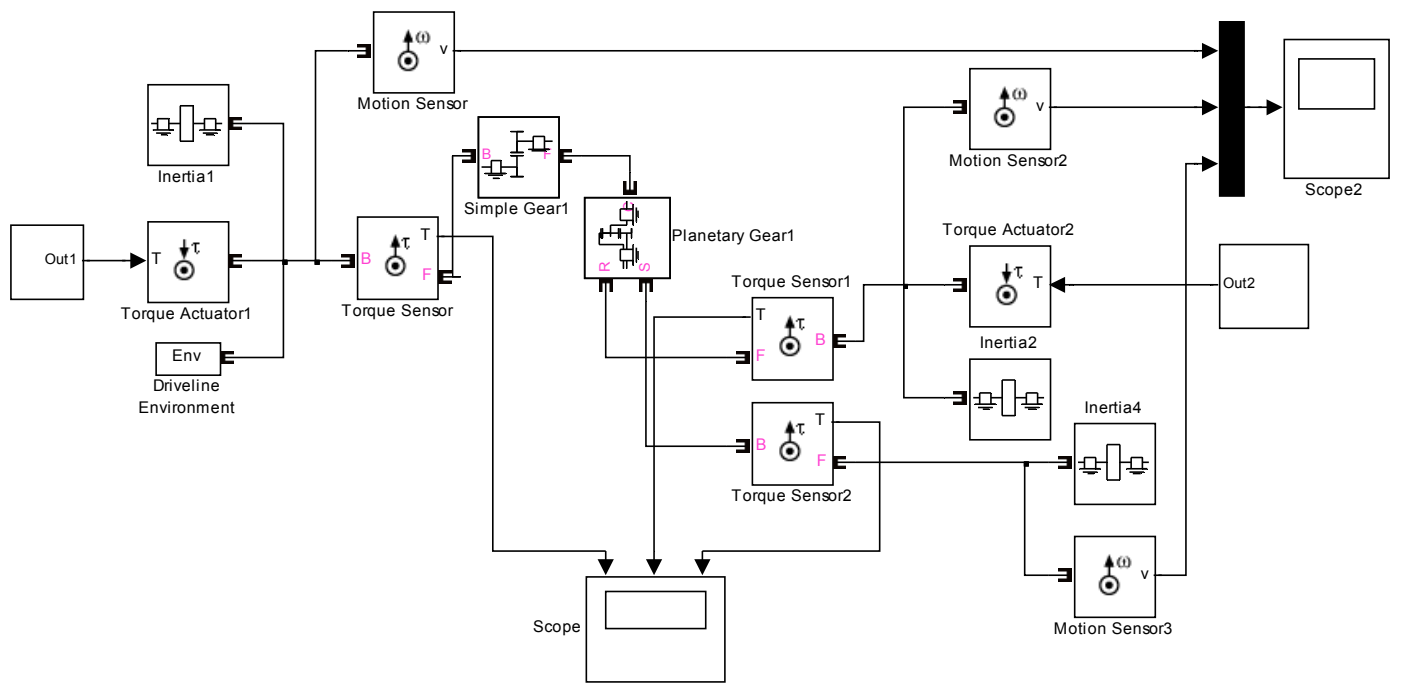

Figure 9. Drive Chain Model of Differential Speed-Regulating Wind Turbine 


\subsubsection{Synchronous Generator Model}

On the basis of the mathematical model and theoretical analysis of synchronous generator, the simulation model of this generator is established in Simulink. The generator has a rated voltage of $690 \mathrm{~V}$, a pole logarithm of 2 pairs, and a rated speed of $1500 \mathrm{r} / \mathrm{min}$. The established model is shown in Figure 10.



Figure 10. Synchronous Generator Model

\subsubsection{Model of Speed-Regulating Motor and Speed Control Method}

The control objectives of speed-regulating motor are to control the speed of generator for meeting the requirements of grid-connected speed before grid-connected mode and control the speed of wind wheel to obtain maximum power after grid-connected mode. The speed-regulating motor adopts asynchronous motor. The speed formula of asynchronous motor is shown as follows.

$$
\begin{gathered}
n=\frac{60 f}{p}=(1-s) \frac{60 f_{1}}{p} \\
s=\frac{f_{2}}{f_{1}}=\frac{f_{1}-f_{M}}{f_{1}}=\frac{n_{0}-n}{n_{0}}
\end{gathered}
$$

In the formula, $f_{1}$ is the stator frequency of asynchronous motor. $f_{2}$ is the slip-frequency of rotor winding of asynchronous motor. $F_{\mathrm{m}}$ is the rotor rotation frequency of asynchronous motor. $n_{0}$ is the synchronous speed. $n$ is the speed of asynchronous motor. $p$ is the pole logarithm of stator winding of asynchronous motor. $s$ is the slip rate. Formula (19) show that, if the slip rate $s$ of the motor is changed, then the speed $n$ of the motor will change accordingly. The use of asynchronous motor in differential-speed control system can achieve stable speed regulation. The essence of speed control of asynchronous motor is the control of electromagnetic torque. Given the randomness of wind speed, the speed of wind turbine must be adjusted constantly, and the inertia of transmission system is large. The speed-regulating process will lead to significant changes in motor load. Therefore, slip-frequency control method should be used. The model of speed-regulating motor is shown in Figure 11. 


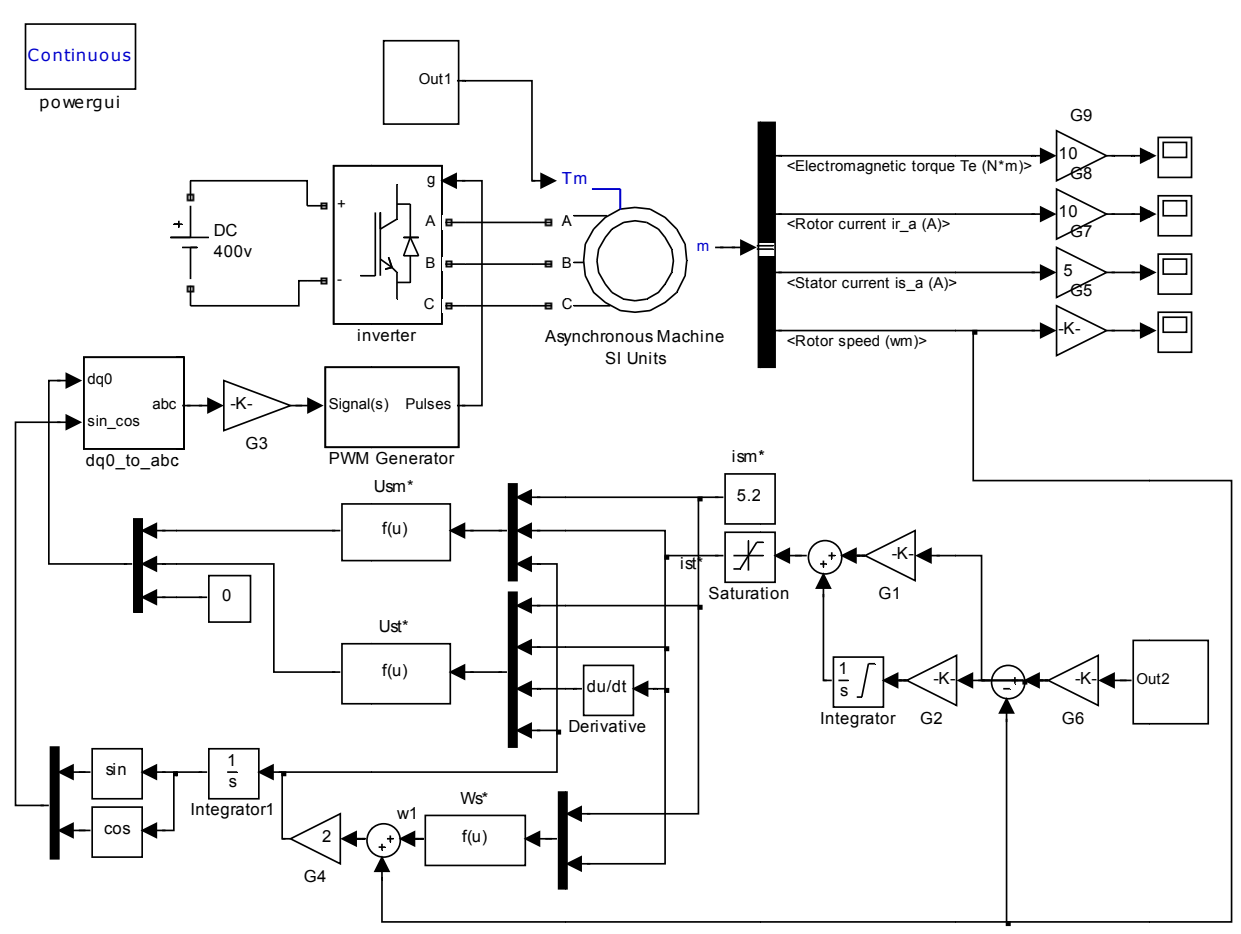

Figure 11. Model of Slip-Frequency Control System for Speed-Regulating Motor

\subsection{Design of Test Panel}

A test-panel for differential speed-regulating wind power system is designed to verify the transmission and control principle of differential speed-regulating wind turbines. The installation arrangement is shown in Figure 12. The software composition of the control system of the test panel is as follows: DAQNavi Driver, Laboratory Instrument Measurement, and Control Software LabVIEW. DAQNavi driver is mainly used to control the data acquisition device and set data sampling type, sampling frequency, and channel number, and so on. Other components include PCI-1780U Yanhua Counting Card; PCI-1716 Multifunctional Data Acquisition Card; PCI-1780U that provides 8-way counter channel, digital output, and digital input; speed and torque sensor signal acquisition; and PCI-1716 that inputs and outputs 16 single-ended analog signals or 8 differential analog signals for collecting speed and torque signals of servo motors.
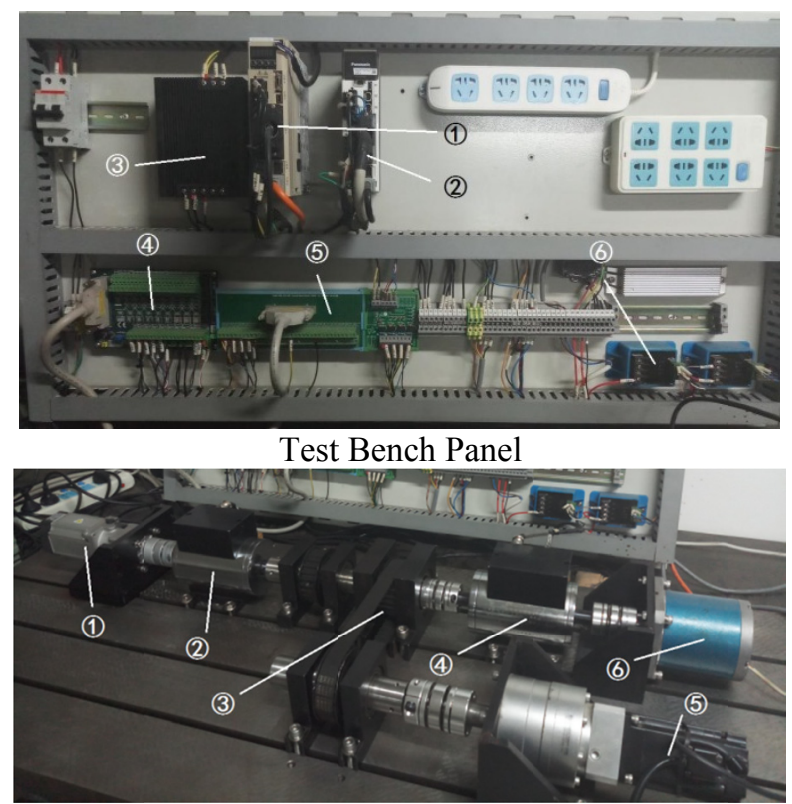

Drive System of Test Panel

Figure 12. Test Platform for Differential-Speed Control Wind Power System 
Notes: Figure 12 (a) (1) Servo Controller of Speed-Regulating Motor; (2) Analog Wind Turbine Servo Controller; (3) 15 V/5 V DC-Regulated Power Supply; (4) Yanhua PCI-1716 Multifunctional Data Acquisition Card; (5) Yanhua PCI-1780U Counting Card; (6) Current transformer.

Figure 12 (b) (1) Simulated Wind Wheel; (2) Torque and Speed Sensor at Input End of Wind Wheel of Moving Gear Box; (3) Differential Gearbox; (4) Differential Gear Box Generator End Torque and Speed Sensor; (5) Speed-Regulating Motor; (6) Synchronous Generator.

\section{Control Strategy of Differential Speed-Regulating Wind Turbine under Typical Conditions}

The control objectives of the typical operation process of the differential speed-regulating wind turbine are as follows.

\section{1)Start-up process}

Synchronous generators accelerate gradually through the speed motor until they reach the speed range required for grid-connected mode. When the system detects that the grid-connected conditions are met, the grid-connected contactor closes and the synchronous generators run in grid-connected mode.

2)Below rated wind speed

At below rated wind speed, the speed of speed-regulating motor is adjusted using the fuzzy control method on the basis of the wind wheel speed, torque, and other signals. Then, the wind wheel speed is adjusted to ensure the optimal speed of maximum wind power of wind wheel.

3)Above rated wind speed

Under this condition, the output power of the unit has reached the rated value and the wind power absorbance by the wind turbine no longer increases. By controlling the blade pitch angle beta, the absorbance power of the wind turbine is limited.

\subsection{Idle Load Grid-Connected Control}

The idle load grid-connected process is simple, efficient, and reliable. Generators run without load before grid-connected mode and meet the grid-connected conditions, such as speed. Then, the wind turbine is loaded after grid-connected mode. Considering the characteristics of differential speed-regulating wind turbines, idle load grid-connected mode is adopted. When the synchronous generator is idle, the electromagnetic torque is zero, the generator does not produce an active power output, and the grid-connected requirement is high. If the voltage amplitudes and frequencies of generator and network sides are equal, then the phase difference is zero. In this case, no impact and disturbance are applied under grid-connected mode, but deviation is unavoidable. Usually, the voltage, angular frequency, and phase values of motor and grid sides are close. Specifically, the voltage deviation does not exceed $5 \%$, the frequency deviation does not exceed $0.2 \mathrm{~Hz}$, and the phase difference does not exceed $5^{\circ}$. No-load grid-connected can be realized if the above-mentioned parameters are satisfied.

\subsection{Rated Load Grid-Connected Control}

\subsubsection{Maximum Power Tracking based on Fuzzy Control Method}

After the unit is connected to the grid, the control target below the rated wind speed is the optimal speed when the wind turbine maintains the maximum wind power. To achieve maximum power tracking operation at rated wind speed for differential speed-regulating wind turbines, the speed of wind turbines must be changed in real time depending on the operation conditions. Moreover, the speed of wind turbines is controlled by adjusting the speed of speed-regulating motors. Therefore, the design of maximum power tracking control system essentially aims to achieve the effective control of speed-regulating motors. Therefore, this study introduces the fuzzy control method and designs the fuzzy controller based on the optimal torque method.

\subsubsection{Structure Design of Fuzzy Controller}

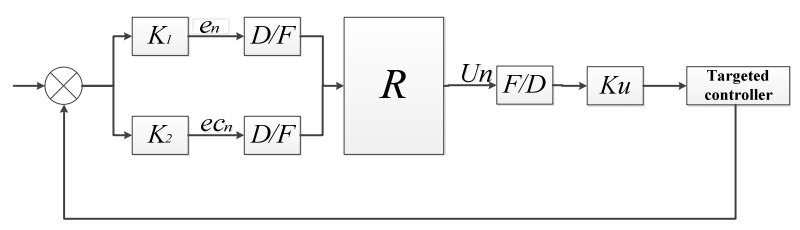

Figure 13. Two-Dimensional Fuzzy Control System with Tracing Function of Maximum Power Output 
A fuzzy controller is usually composed of the fuzzy interface, a database, a criteria database, the logical mechanism, and the output display interface. In fuzzy control, the fuzzy and clarifying modules are two important components. Ambiguity refers to the process of transforming ambiguity into clarity. Considering the input and output of the controller, the maximum power tracking fuzzy controller of the differential speed-regulating wind turbine can adopt the double input and single output design to satisfy the control requirements. The ratio of wind turbine torque to speed is measured by torque and speed sensors and then compared with the optimal ratio $K$ of torque and speed. Accordingly, the variation rate of $K$ value deviation is obtained. The change rate of $K$ value deviation is the input of the fuzzy controller, and the regulated speed output is selected by the controller depending on the control rules. The input quantity $e_{n}$ in the figure above represents the deviation of the $K$ value between the $n$ and $n-1$ times. The input $e_{c n}$ denotes the variation rate of the $K$ value deviation between the $n$ and $n-1$ times. The output $U_{n}$ represents the actual value of speed change at the $n$ time. The schematic of the two-dimensional maximum power tracking fuzzy control system is shown in Figure 13.

\subsubsection{Parameter Definition of Fuzzy Controller}

A low-pass filter is added to the output of wind turbine torque to improve the random fluctuation of wind turbine torque caused by the randomness of wind speed, and the processed torque signal is used as the input of the fuzzy controller.

\subsubsection{Determination of the Optimum Torque-Speed Ratio}

Some uncertainties exist in wind speed measurement, and establishing an accurate relationship between wind speed and wind turbine speed is difficult. To eliminate the direct influence of wind speed on wind turbine speed, the following power expression (20) can be modified to replace the wind speed variable as follows.

$$
P_{\text {opt }}=\frac{1}{2} \rho \mathrm{v}^{3} \pi \mathrm{R}^{2} \mathrm{C}_{\mathrm{pmax}}=\frac{1}{2} \rho \mathrm{v}^{3} \pi \mathrm{R}^{2} f\left(\lambda_{\text {opt }}\right)
$$

In the formula, Popt is the maximum wind power, CPmax is the maximum wind energy utilization factor, $R$ is the radius of the wind wheel, $v$ is the wind speed, $\lambda$ opt is the optimum tip speed ratio, and $\rho$ is the air density.

In accordance with the maximum wind energy utilization coefficient CPmax and the blade tip speed ratio $\lambda$ opt, the Popt is thus been calculated. Then, the angular velocity $\omega$ is used to replace the wind speed $v$. The following expressions are deduced as follows.

$$
\begin{gathered}
T_{o p t}=K_{o p t} \omega_{o p t}{ }^{2} \\
K_{o p t}=\frac{\rho R^{5} \pi C_{p \max }}{2 \lambda_{o p t}{ }^{3}}
\end{gathered}
$$

In the formula, Topt is the wind wheel torque under the maximum wind energy utilization factor and Kopt is the optimal torque-speed ratio. Formula (21) shows that, when the wind turbine reaches the maximum utilization factor of wind energy, the torque of the wind turbine is proportional to the square of the angular velocity of the wind turbine. Therefore, the maximum wind energy utilization factor can be achieved by controlling the ratio between the torque and the square of the rotational speed of the wind turbine to achieve the optimal ratio of the torque to the rotational speed under the condition of constant air density. The data in Table 1 show that Kopt $=1.923 \times 10^{5}$ can be obtained by substituting parameters $C_{P \max }, \rho, R$, and $\lambda$ opt into Equation (22). The actual $K$ value can be obtained by measuring the actual wind turbine torque and speed. The difference between the actual $K$ and Kopt values is the $K$ value deviation input of the fuzzy controller.

\subsubsection{Determination of Membership Function}

1)Selection of Seven Fuzzy Subsets based on K Value Deviation: PB, PM, PS, ZO, NS, NM, and NB. The range of values used to cover inputs $(-6,6)$ and the membership functions are shown in Figure 14 (a).

2)Selection of Five Fuzzy Subsets based on the Variation Rate of K Value Deviation: PB, PS, ZO, NS, and NB. The range of values used to cover inputs $(-6,6)$ with the influence degree of wind speed variation and the membership functions are shown in Figure 14 (b).

3)The outputs are the universe (-6,6), PB, PM, PS, ZO, NS, NM, and NB. The corresponding distribution of membership functions is shown in Figure 14 (c). The fields of input and output variables, the names of fuzzy 
subsets covering the fields of variables, the types of membership functions, and the parameters of function inflection points are shown in Table 3.



Distribution of Membership Function of K Value Deviation Input



Distribution of Subordinate Function of K Value Deviation Variation Rate Input

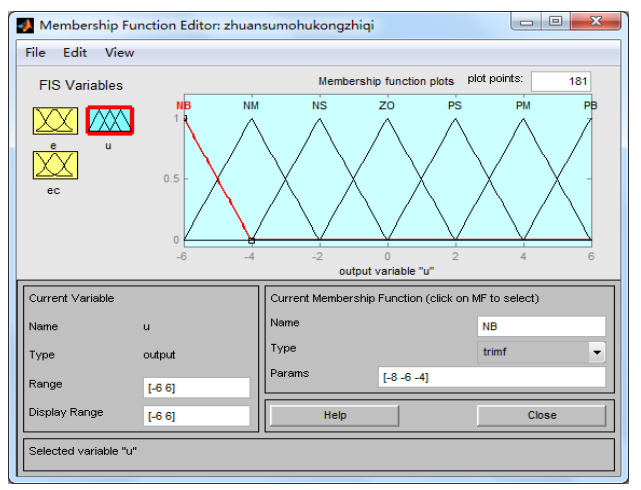

Distribution of Output Subordinate Function

Figure14. Membership function distribution 
Table 3. Fuzzy Universe of Input-Output Variables and Relevant Parameters

\begin{tabular}{lllll}
\hline \multirow{2}{*}{$\begin{array}{llll}\text { Variable name } \\
\text { discourse }\end{array}$} & $\begin{array}{l}\text { of } \\
\text { Names of fuzzy } \\
\text { subsets }\end{array}$ & Subset type & Function parameter \\
\hline \multirow{4}{*}{ Input variables $e$} & {$[-6,6]$} & PB & Trapezoid & {$[3,5,6,7]$} \\
& & PM & & {$[1,3,6]$} \\
& & PS & & {$[0,1,3]$} \\
& & ZO & Triangle & {$[-1,0,1]$} \\
& & NS & & {$[-3,-1,0]$} \\
Input variables & & NM & & {$[-6,-3,-1]$} \\
$e_{c}$ & & NB & Trapezoid & {$[-7,-6,-5,-3]$} \\
& & PB & & {$[1,6]$} \\
& & PS & & {$[1,3]$} \\
& & ZO & Gaussian & {$[1,0]$} \\
& & NS & & {$[1,-3]$} \\
& & NB & & {$[1,-6]$} \\
Output variables & {$[-6,6]$} & PB & & {$[4,6,8]$} \\
$u$ & & PM & & {$[2,4,6]$} \\
& & PS & & {$[0,2,4]$} \\
& & ZO & Triangle & {$[-2,0,2]$} \\
& & NS & & {$[-4,-2,0]$} \\
& & NM & & {$[-6,-4,-2]$} \\
& & NB & & {$[-8,-6,-4]$} \\
\hline
\end{tabular}

\subsubsection{Establishment of Fuzzy Rules for Controllers}

In this study, Mamdani Min-Max method is used, and five basic fuzzy rules are summarized according to practical experience:

(1) If the deviation of $K$ value is positive, then the speed of speed-regulating motor will increase rapidly. (2) If the deviation of $K$ value is negative, then the speed of speed-regulating motor can be decreased rapidly. (3) If the $K$ value is the best, then the speed of the speed-regulating motor will not change. (4) If the $K$ value is optimal and the $K$ value deviation rate is positive, then the speed of speed-regulating motor will increase slowly. (5) If the $K$ value is optimal and the $K$ value deviation change rate is negative, then the speed of speed-regulating motor will decrease slowly.

As mentioned above, the $K$ value deviation is divided into seven grades, and the $K$ value deviation change rate is divided into five grades. After the combination of the two, the fuzzy rules shown in Table 4 can be established. After the fuzzy control rules are established, the schematic of the input and output relation surface of the fuzzy reasoning is shown in Figure 15. If the relation surface is smooth, then the setting of the control rules is reasonable. The slope of surface change near the equilibrium point is large. Thus, the control sensitivity at the equilibrium point is high, which is consistent with the design purpose.

Table 4. Decision Making of Fuzzy Criterion

\begin{tabular}{llllllll}
\hline $\mathrm{e}_{\mathrm{c}} / \mathrm{e} / \mathrm{u}$ & $\mathrm{NB}$ & $\mathrm{NM}$ & $\mathrm{NS}$ & $\mathrm{ZO}$ & $\mathrm{PS}$ & $\mathrm{PM}$ & $\mathrm{PB}$ \\
\hline $\mathrm{NB}$ & $\mathrm{NB}$ & $\mathrm{NB}$ & $\mathrm{NB}$ & $\mathrm{NM}$ & $\mathrm{NM}$ & $\mathrm{NS}$ & $\mathrm{ZO}$ \\
$\mathrm{NS}$ & $\mathrm{NB}$ & $\mathrm{NM}$ & $\mathrm{NM}$ & $\mathrm{NS}$ & $\mathrm{ZO}$ & $\mathrm{PS}$ & $\mathrm{PM}$ \\
$\mathrm{ZO}$ & $\mathrm{NM}$ & $\mathrm{NM}(1)$ & $\mathrm{NS}(3)$ & $\mathrm{ZO}$ & $\mathrm{PS}$ & $\mathrm{PM}$ & $\mathrm{PM}$ \\
$\mathrm{PS}$ & $\mathrm{NM}$ & $\mathrm{NS}(2)$ & $\mathrm{ZO}(4)$ & $\mathrm{PS}$ & $\mathrm{PM}$ & $\mathrm{PM}$ & $\mathrm{PB}$ \\
$\mathrm{PB}$ & $\mathrm{ZO}$ & $\mathrm{PS}$ & $\mathrm{PM}$ & $\mathrm{PM}$ & $\mathrm{PB}$ & $\mathrm{PB}$ & $\mathrm{PB}$ \\
\hline
\end{tabular}






Figure 15. Curve Surface of Input-Output with Fuzzy Logic

\subsubsection{Output Value of Fuzzy Quantity}

Fuzzy rules are not always activated under a certain input. Approximate reasoning is used to calculate the output value of the fuzzy quantity for simplifying the calculation. If the measured input is $e^{=-2}$ and $e_{c}=2$ at a certain time, then the fuzzy subset NM and NS can be mapped by the fuzzy method of the definition $e=-2$ depending on the distribution of the membership function of the input deviation of $K$ value. In accordance with the distribution of membership function of input variable of $K$ value deviation rate of change, the definition $e_{c}=2$ is carried out by fuzzy method and mapped to fuzzy subsets NB and NM of $e_{c}$. From the above-mentioned table of fuzzy rules, four fuzzy rules can be used at this time. The four fuzzy rules are as follows.

1) if $e$ is $\mathrm{NM}$ and $e_{c}$ is $\mathrm{ZO}$ then $u$ is $\mathrm{NM}(1)$

2) if $e$ is NM and $e_{c}$ is PS then $u$ is $\mathrm{NS}(2)$

3 ) if $e$ is $\mathrm{NS}$ and $e_{c}$ is $\mathrm{ZO}$ then $u$ is $\mathrm{NS}(3)$

4) if $e$ is NS and $e_{c}$ is $\mathrm{PS}$ then $u$ is $\mathrm{ZO}(4)$

The four fuzzy criteria of $\mathrm{NM}(1), \mathrm{NS}(2), \mathrm{NS}(3)$ and $\mathrm{ZO}(4)$ can be seen in Table 4.

For control rule (1), the output is $U_{I}(u), \mathrm{NM}(-2)=0.5, \mathrm{ZO}(2)=0.1353$. Thus, the output is

$$
\begin{aligned}
& U_{1}(u)=(\vec{A})^{T} \circ R_{1}=(N M(-2) \wedge Z O(2)) \circ R_{1}(u) \\
& =N M(-2) \wedge Z O(2) \wedge N M(u)=(N M(-2) \wedge Z O(2)) \wedge N M(u) \\
& =0.1353 \wedge N M(u)=(0.1353 N M)(u)
\end{aligned}
$$

For control rule (2), the output is $U_{2}(u)$, which is $\mathrm{NM}(-2)=0.5, \operatorname{PS}(2)=0.6015$. Therefore, the output is

$$
\begin{aligned}
& U_{2}(u)=(\vec{A})^{T} \circ R_{2}=(N M(-2) \wedge P S(2)) \circ R_{2}(u) \\
& =N M(-2) \wedge P S(2) \wedge N S(u)=(N M(-2) \wedge Z O(2)) \wedge N S(u) \\
& =0.5 \wedge N S(u)=(0.5 N S)(u)
\end{aligned}
$$

For control rule (3), the output is $U_{3}(u)$, which is $\mathrm{NS}(-2)=0.25, \mathrm{ZO}(2)=0.1353$. Thus, the output is

$$
\begin{aligned}
& U_{3}(u)=(\vec{A})^{T} \circ R_{3}=(N S(-2) \wedge Z O(2)) \circ R_{3}(u) \\
& =N S(-2) \wedge Z O(2) \wedge N S(u)=(N S(-2) \wedge Z O(2)) \wedge N S(u) \\
& =0.1353 \wedge N S(u)=(0.1353 N S)(u)
\end{aligned}
$$

For control rule (4), the output is $U_{4}(u)$, which is $\mathrm{NS}(-2)=0.25, \operatorname{PS}(2)=0.6015$. Therefore, the output is

$$
\begin{aligned}
& U_{2}(u)=(\vec{A})^{T} \circ R_{2}=(N S(-2) \wedge P S(2)) \circ R_{2}(u) \\
& =N S(-2) \wedge P S(2) \wedge Z O(u)=(N S(-2) \wedge P S(2)) \wedge Z O(u) \\
& =0.25 \wedge Z O(u)=(0.25 Z O)(u)
\end{aligned}
$$

The fuzzy subset $U(u)$ of the final total output can be expressed as 


$$
\begin{aligned}
& U(u)=U_{1}(u) \cup U_{2}(u) \cup U_{3}(u) \cup U_{4}(u) \\
& =(0.1353 \mathrm{~N} M)(u) \cup(0.5 N S)(u) \bigcup(0.1353 \mathrm{VS})(u) \cup(0.25 Z O)(u)
\end{aligned}
$$

After each output fuzzy subset is obtained, the total output can be obtained, as shown in Figure 16.

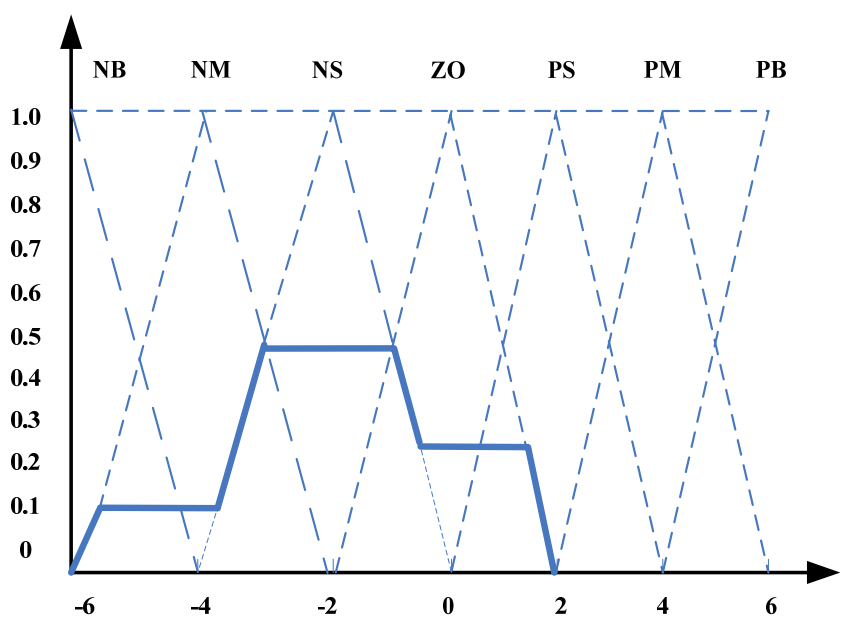

Figure 16. Derivative Fuzzy Subset

Figure 16 shows that the total output is a fuzzy subset with a membership function of an irregular shape in $(-6,2)$. The maximum membership method is used to clarify the ambiguity for controlling the speed of speed-regulating motor. Figure 16 shows that the maximum membership degree is 0.5 on the domain $(-6,2)$, and the corresponding abscissa points are set to $\left(u_{1}, u_{2}\right)$, which satisfies $\operatorname{NS}\left(U_{1}\right)$ NS $\left(U_{2}\right)=0.5$. The corresponding membership function equation is

$$
N S(u)=\left\{\begin{array}{l}
\frac{1}{2}(u+3),-4 \leq u \leq-2 \\
-\frac{1}{2} u,-2 \leq u \leq 0
\end{array}\right.
$$

Then,

$$
\left\{\begin{array}{l}
\frac{1}{2}(u+3)=0.5 \\
-\frac{1}{2} u=0.5
\end{array}\right.
$$

By solving the above-mentioned equations, we can obtain

$$
\left\{\begin{array}{l}
u_{1}=-2 \\
u_{2}=-1
\end{array}\right.
$$

From the aforementioned deduction, the corresponding time interval of maximum membership degree is from -1 to -2 , and all other output ambiguity values can be obtained by calculation. On the basis of the model of wind power system, the model of fuzzy control system is established using the modules of Fuzzy Logic Toolbox in Simulink, as shown in Figure 17. 


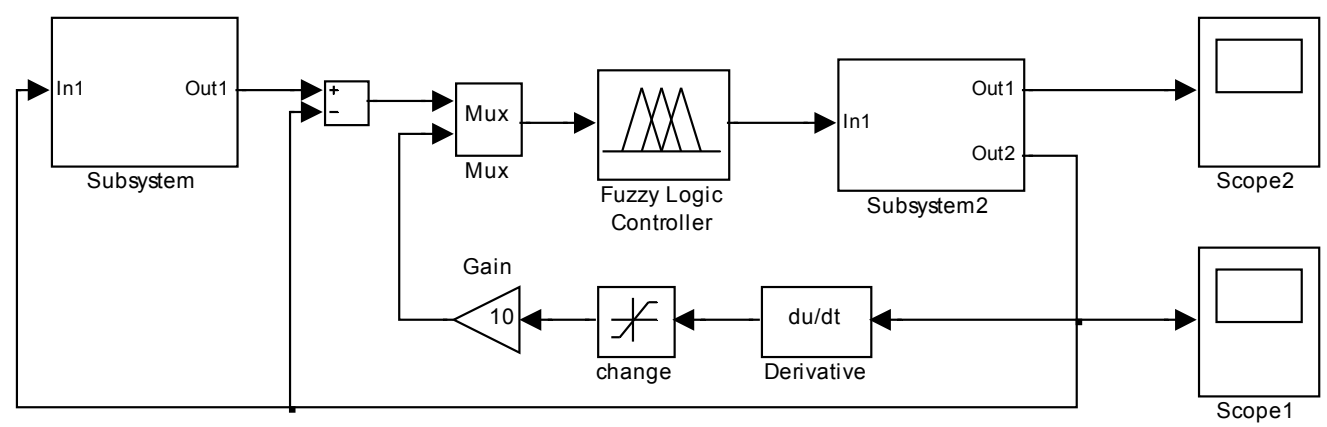

Figure 17. Simulink Simulation Model of Fuzzy Control

\subsection{Unit Control with Exceed Rated Wind Speed}

The wind power absorbance by the wind turbine should be limited when the wind speed exceeds the rated wind speed to ensure the safe and stable operation of the unit. When surpass the rated wind speed, the power control of the unit generally adopts the pitch-changing mode. The speed-regulating motor of the differential speed-regulating wind turbine will no longer adjust the speed, and the pitch-changing mode will be adopted to control the absorbance power of the wind turbine. This condition is the same as that for the control object and target of the typical speed-changing units in the past, and the same pitch-changing mode can be used to control the power as the general units.

\section{Simulation and Experimental Analysis}

\subsection{Simulation Analysis}

\subsubsection{Simulating Analysis of Basic Operation Characteristics of Speed-Regulating Motor}

Generator speed is an important control target of a no-load grid-connected unit. At this time, the control object is speed-regulating motor, and simulation analysis is conducted on the operation characteristics of speed-regulating motor. The simulation time is $5 \mathrm{~s}$, the sampling time is $0.00001 \mathrm{~s}$, the simulation algorithm is ode 5 , and the initial speed of speed-regulating motor and wind turbine is $0 \mathrm{r} / \mathrm{min}$.

1)The simulation results of speed control motor show that the change in speed is a linear process, as shown in Figure 18 (a). In the time interval of $0-3.5 \mathrm{~s}$, the speed-regulating motor drives the generator to increase its speed gradually. At $3.5 \mathrm{~s}$, the synchronous speed of the generator is reached, and the speed of the speed-regulating motor is then stabilized at $500 \mathrm{r} / \mathrm{min}$.

2)The simulation results of electromagnetic torque of speed-regulating motor are shown in Figure 18 (b). The maximum instantaneous electromagnetic torque of the speed-regulating motor is approximately $1.4 \mathrm{kN} . \mathrm{m}$ after starting. The variation in the electromagnetic torque during the speed-increasing process is small and fluctuates mainly in the range of $0.6-1 \mathrm{kN} . \mathrm{m}$, which indicates that the speed-increasing process runs smoothly. Starting from $3.5 \mathrm{~s}$, the electromagnetic torque is very small because the energy loss during the transmission operation is offset.

3)The simulation results of stator current of speed-regulating motor are shown in Figure 18 (c). In the time interval of $0-3.5 \mathrm{~s}$, the stator current value increases slowly with the speed of speed-regulating motor and the current frequency increases gradually. After the speed stabilizes, the stator current value decreases rapidly. 


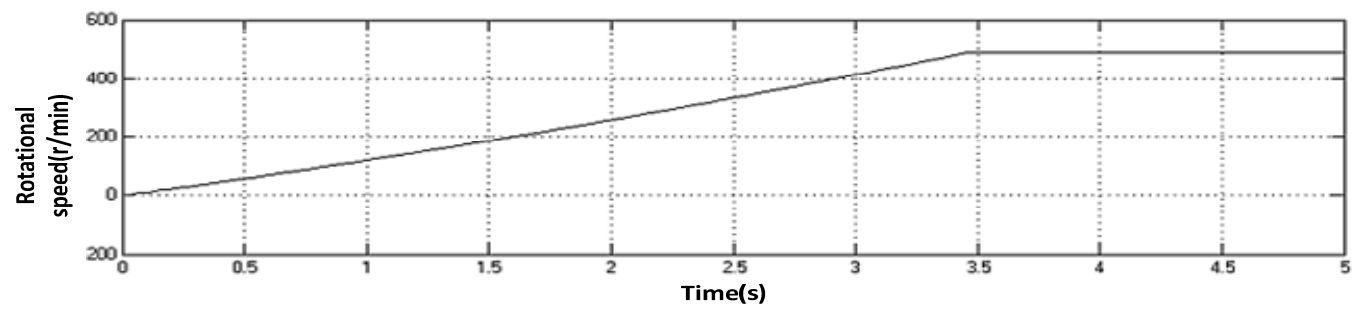

Simulation Results of Speed Control Motor

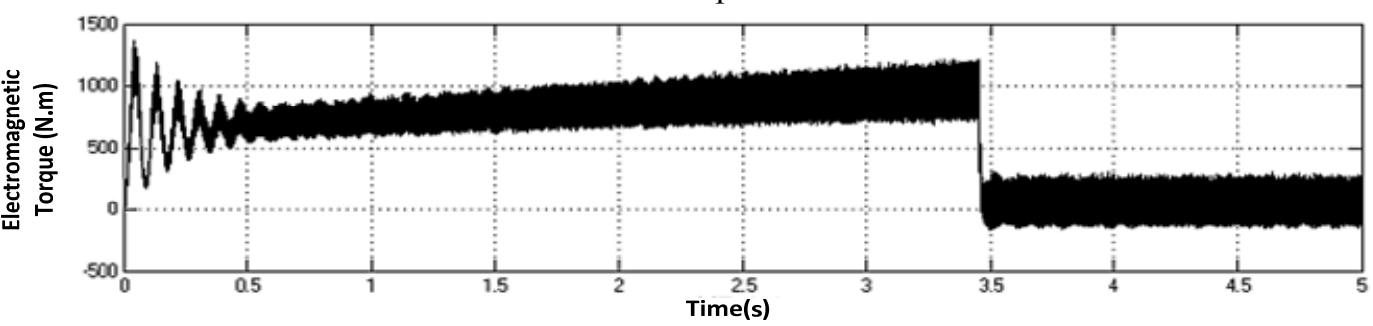

Simulation Results of Electromagnetic Torque of Speed-Regulating Motor



Simulation Results of Stator Current of Speed-Regulating Motor

Figure 18. Simulation Results of Basic Operating Characteristics of Speed Control Motor

\subsubsection{Simulation and Analysis of Maximum Power Tracking Operation Characteristics of Units}

The speed of the wind turbine directly affects the ability of the unit to capture wind energy. The relationship between the torque and rotational speed of the wind turbine in operation is obtained by taking the steady-changing wind speed model as the input wind speed. When the speed of the wind turbine is less than $6 \mathrm{r} / \mathrm{min}$, the torque is zero. At this time, the wind turbine is in free rotation and the generator is not connected to the grid. When the speed of the wind turbine reaches or exceeds $6 \mathrm{r} / \mathrm{min}$, the generator is connected to the grid. At this time, the wind turbine needs to overcome the reaction force produced by the generator. With the increase in wind speed, the speed of the wind turbine is also rising and the torque is rising synchronously. On the basis of the combined wind speed model, the maximum power of the wind turbine is simulated to track the change in the speed during operation, and the curve of the speed of the wind turbine is obtained, as shown in Figure 19 (b). The simulation setting time is $60 \mathrm{~s}$, and the sampling time is $0.01 \mathrm{~s}$. At $5 \mathrm{~s}$ before the simulation, the speed of the wind wheel increases gradually and the wind wheel approaches the maximum wind energy utilization coefficient. With the increase in the speed of the wind wheel and the optimal speed, the change trend of the speed of the wind wheel is the same as that of the wind speed. In tracking the maximum power, the speed regulation of the wind wheel is realized by adjusting the speed of the speed-regulating motor. The input wind speed of the simulation model is composed of the combined wind speeds. The simulation results of the speed of the speed-regulating motor in operation are shown in Figure 19 (c). The speed change direction of speed-regulating motor is the same as that of wind turbine, which is consistent with the operation characteristics of components of differential speed-regulating mechanism. The steady-state characteristics of the maximum power tracking process of differential speed-regulating wind power system are analyzed, and the simulation results are shown in Figure 19 (d). The actual output power coincides with the theoretical output power when the wind speed is high. As a result, an improved maximum power tracking effect is achieved. The variation in wind energy utilization coefficient is shown in Figure 19 (e). Under the rated wind speed, the system can maintain the maximum wind energy utilization coefficient. After the rated power is reached, the wind energy utilization coefficient decreases rapidly as the wind speed continues to increase. 


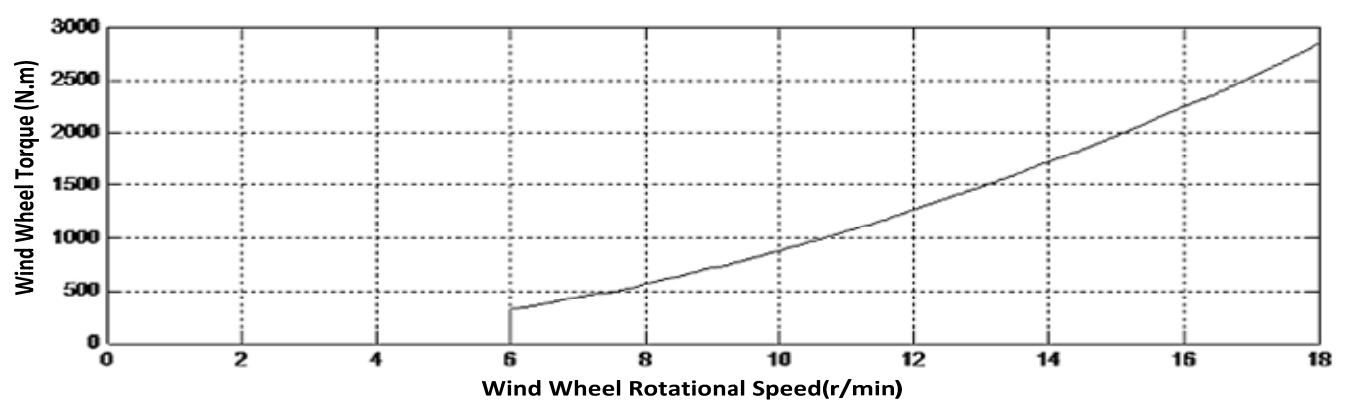

(a)Torque-Speed Relationship of Wind Turbine Operation

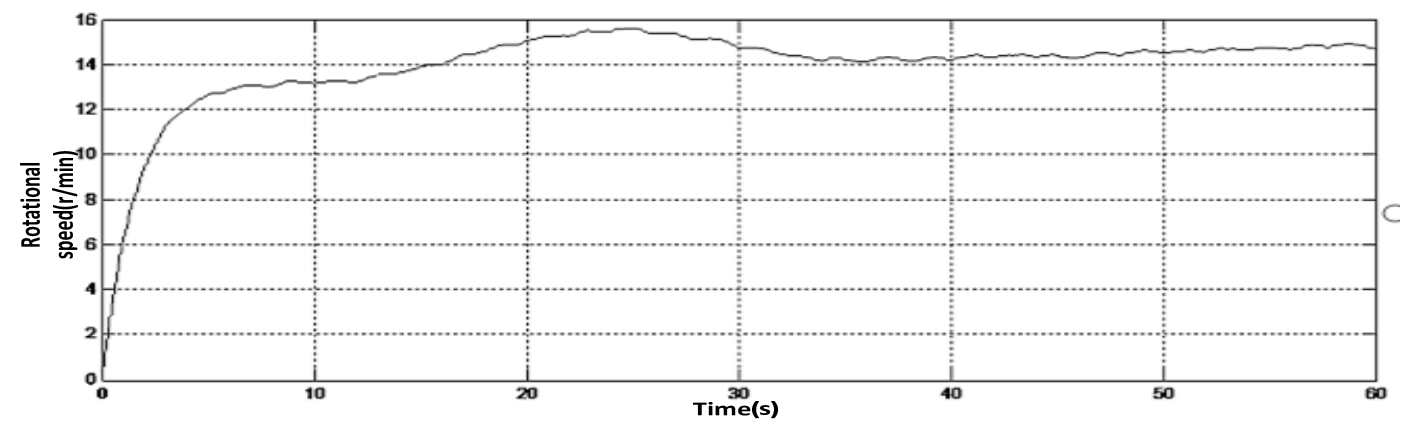

(b)Wind Turbine Speed Simulation

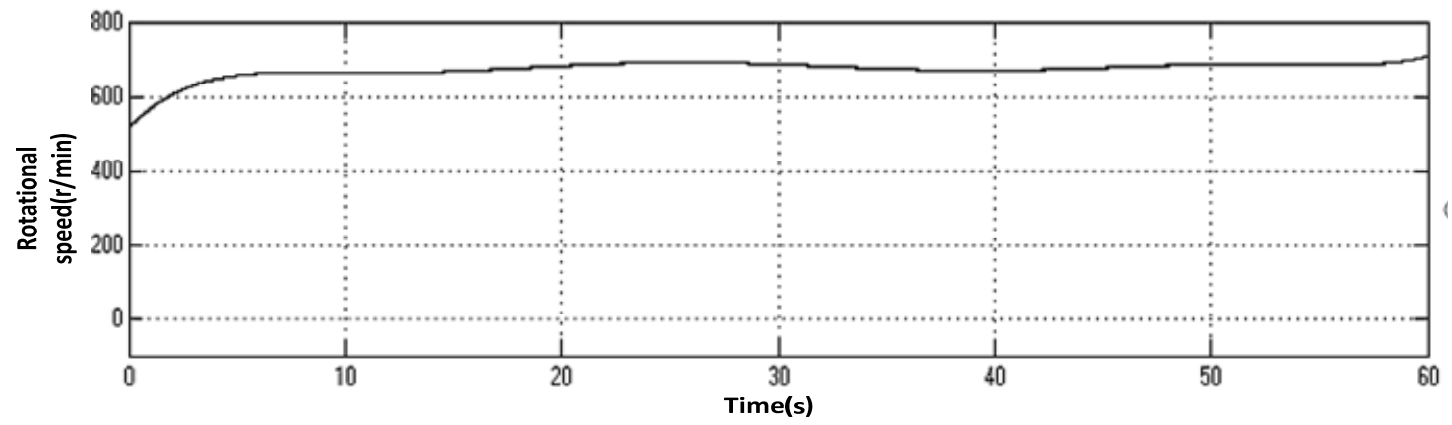

(c) Speed Control Motor

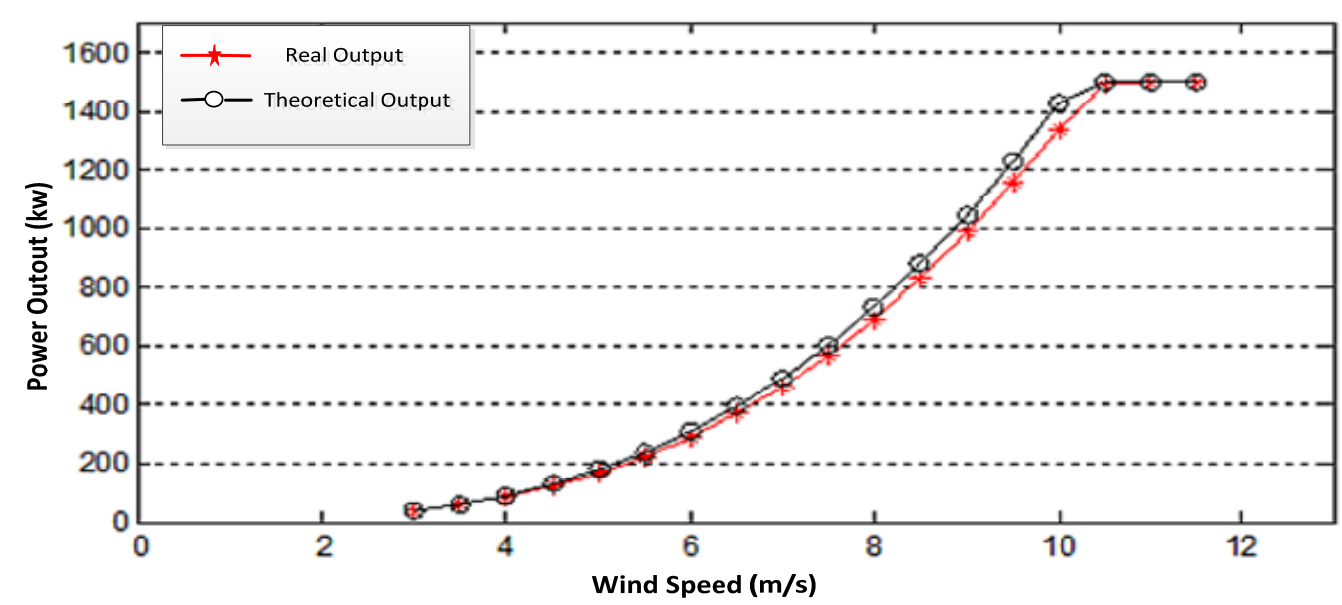

Comparison of Actual Output Power and Theoretical Output Power 


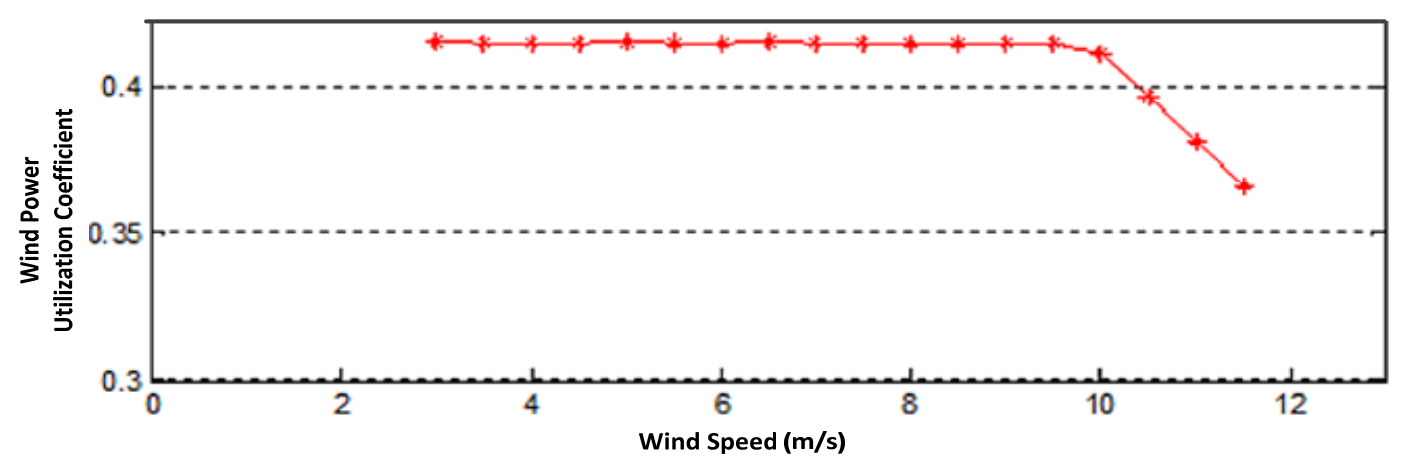

Variation in Wind Energy Utilization Coefficient of Wind Turbine

Figure 19. Simulation Results of Differential-Speed Control Wind Power System

\subsection{Test Analysis of Grid-Connected Control of Test Panel}

\subsubsection{Speed Analysis of Generator on Test Panel}

The differential speed-regulating wind power system test rig is used to test the operation of the generator before it is connected to the grid. Meanwhile, the operation speed of the generator is measured. The measurement results are shown in Figure 20.

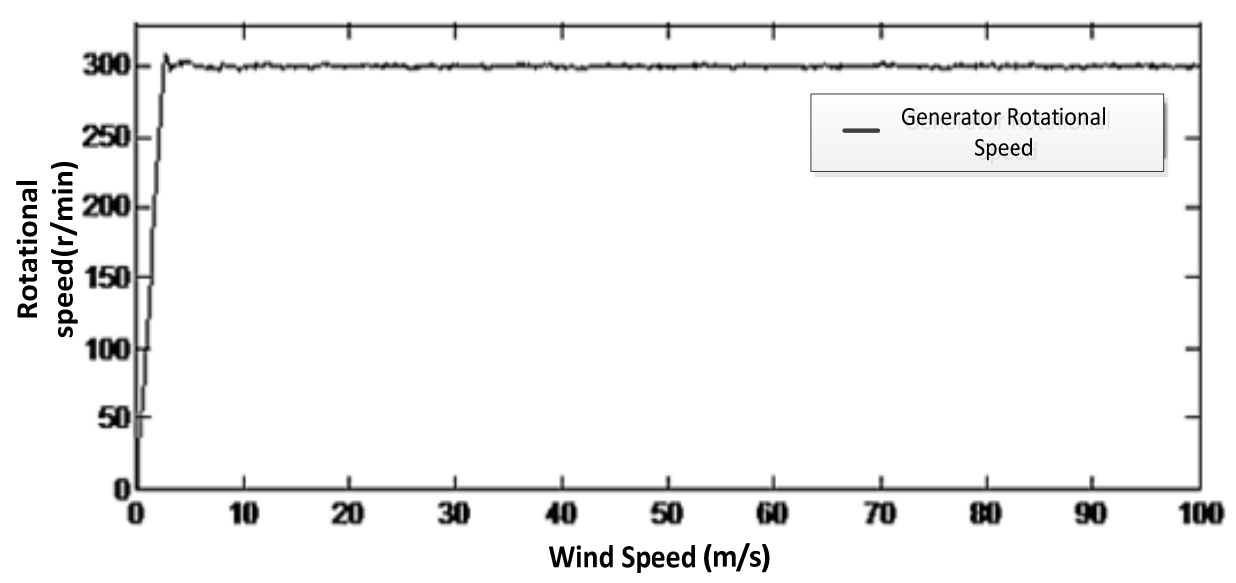

Operating Speed of Generator

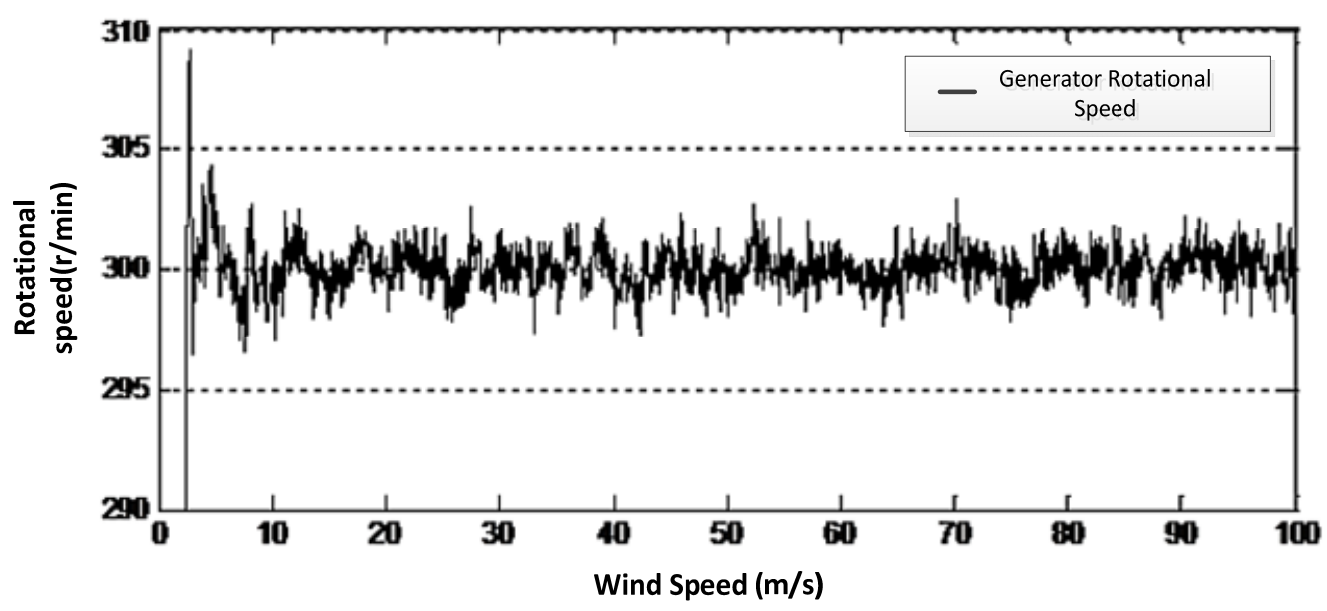

Amplification Diagram of Generator Operating Speed

Figure 20. Operating Speed of the Generator before it is Connected to the Grid 
The test results show that, when the generator is running for approximately $3.5 \mathrm{~s}$, the speed of the generator reaches the rated operating speed, and then, the speed is maintained near $300 \mathrm{r} / \mathrm{min}$. Therefore, the generator of the differential-speed control wind power system test panel can maintain constant speed operation.

\subsubsection{Analysis of Output Voltage of Generator for Idle Load Grid-Connected Test}

The power output of the generator must meet certain requirements to connect the generator to the grid smoothly. The oscilloscope is connected to the generator and grid sides to measure the output voltage waveform of the generator for observing the power output of the generator intuitively (See Figure 21).

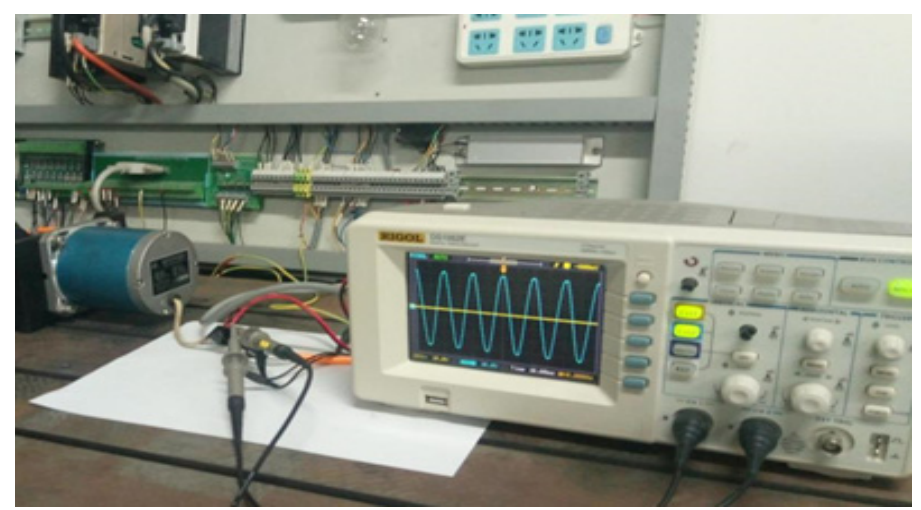

Figure 21. Cable Connection of Generator Output Measurement Device

\section{Conclusion}

1)The simulation models of wind wheel, transmission chain, speed-regulating motor, and generator are established for differential speed-regulating wind turbine, and the operation characteristics of speed-regulating motor are simulated and analyzed. The simulation results show that the speed of the speed-regulating motor varies linearly. The synchronous speed of the motor is reached at $3.5 \mathrm{~s}$, and the speed of the speed-regulating motor stabilizes at $500 \mathrm{r} / \mathrm{min}$. After the maximum instantaneous electromagnetic torque is reached at the start of the speed-regulating motor, it fluctuates mainly in the range of $0.6-1 \mathrm{kN} . \mathrm{m}$ with a small variation during the subsequent speed-increasing process. This condition indicates that the speed-increasing process runs smoothly. The stator current value increases slowly with the speed of the speed-regulating motor in the time range of $0-3.5 \mathrm{~s}$ and then decreases rapidly after the speed stabilizes.

2)On the basis of slip-frequency and fuzzy control theories, a wind power control system with differential speed regulation is designed. On the basis of the combined wind speed model, the simulation analysis of the variation in the wind speed during the maximum power tracking operation of the wind turbine is carried out. The simulation results show that, in the first $5 \mathrm{~s}$ of the simulation, the speed of the wind wheel increases gradually and the wind wheel approaches the maximum wind energy utilization factor gradually. With the increase in the speed of the wind wheel and the optimal speed, the change trend of the speed of the wind wheel is the same as that of the wind speed. The actual output power coincides with the theoretical output power when the wind speed is high. As a result, an improved maximum power tracking effect is achieved. The system can display a satisfactory performance of maintaining the maximum wind energy utilization factor when the wind speed below the rated wind speed, as compared to the condition when the wind speed beyond the rated wind speed.

3)A test bench for grid-connected control of differential speed-regulating wind turbines is built for test analysis. The test results show that, when the generator runs at approximately $3.5 \mathrm{~s}$, its speed reaches the rated speed and is maintained at $300 \mathrm{r} / \mathrm{min}$. Therefore, the generator of the test panel can maintain constant speed operation. The test output of the generator speed, generator output frequency, voltage, and other parameters of the differential-speed control wind power system show that these parameters are consistent with those of the grid, meet the grid-connected requirements, and achieve satisfactory results. Therefore, the fuzzy control system can realize no-load grid-connected mode.

\section{Acknowledgments}

We would like to thank En-papers for English language editing.

\section{References}

Clemens, H. \& Wout, W. (2019). Validations of Improved Sampling Concepts for Offshore Wind Turbine Fatigue Design. Energies, 12(603). https://doi.org/10.3390/en12040603 
Huang, L., Xin, H. \& Zhang, L. (2017). Synchronization and Frequency Regulation of DFIG-based Wind Turbine Generators with Synchronized Control. IEEE Transactions on Energy Conversion, (99),1-1. https://doi.org/10.1109/TEC.2017.2675480

Idan, M. \& Lior, D. (2000). Continuously Variable Speed Wind Turbine Transmission Concept and Robust Control. Wind Energy, 24(3),151-167. https://doi.org/10.1260/0309524001495530

Jelaska, D., Podrug, S. \& Perku, I. M. (2015). A novel hybrid transmission for variable speed wind turbines. Renewable Energy, 83, 78-84. https://doi.org/10.1016/j.renene.2015.04.021

Krupke, C., Wang, J. \& Clarke, J. (2017). Modeling and Experimental Study of a Wind Turbine System in Hybrid Connection with Compressed Air Energy Storage. IEEE Transactions on Energy Conversion, 32(1), 137-145. https://doi.org/10.1109/TEC.2016.2594285

Li, S. \& Zhu, G. (2017). Pitch angle adjustment to wind turbine generators for frequency regulation based on eigenvalue analysis. Acta Energiae Solaris Sinica, 34(2), 89-96

Li, L. (2010). Research on speed controlling technology and devices based on distributed power train principle. North China Electric Power University (Beijing).

Mangialardi, L. \& Mantriota, G. (1999). Power flows and efficiency in infinitely variable transmissions. Mechanism \& Machine Theory, 34(7), 973-994. https://doi.org/10.1016/S0094-114X(98)00089-5

Wu, X., Su, R. \& Rui, X. (2014). Design of hydro-mechanical principle based variable-speed transmission for grid-connected wind turbune. Acta Energiae Solaris Sinica, 35(1), 113-118.

Wu, X., Su, R., Rui, X. \& Lu, C.(2015). Dynamic Modelling and Simulation of a Novel Grid-connected Wind Turbine. Journal of Chinese Society of Power Engineering, 35(11), 934-943.

Ran, B., Cheng, Z. \& Donald M.H. (2017). Detection and classification of faults in pitch-regulated wind turbine generators using normal behaviour models based on performance curves. Renewable Energy, 105, 674-688. https://doi.org/10.1016/j.renene.2016.12.075

Report on China wind power industry in 2018 (2018). Polaris research centre of electricity data.

Rui, X., Su, R. \& Wu, X. (2014). The conceptual design of grid-connected wind turbine based on speed regulating differential mechanism. Journal of Mechanical Science \& Technology, 28(6), 2215-2220. https://doi.org/10.1007/s12206-014-0510-y

Sainz, L., Monjo, L. \& Pedra, J. (2017). Effect of wind turbine converter control on wind power plant harmonic response and resonance. IET Electric Power Applications, 11(2),157-168. https://doi.org/10.1049/iet-epa.2016.0241

Su, R., Yang, Q., Liu, P., Li, H., Huang, Y. \& Wang, J. (2019). Research of Modelling and Dynamic Characteristics for Wind Turbine Transmission with Differential Speed Regulation. Journal of Yantai University, 32(1), 79-83.

Su, R., Liu, P., Li, H., Huang, Y. \& Wang, J. (2018). The Test Study of Transmission principle for novel wind turbine. Renewable Energy Resources, 36(7), 1086-1091.

Tang, X \& Yin, M. (2018). Active Power Control of Wind Turbine Generators via Coordinated Rotor Speed and Pitch Angle Regulation.10.1109/TSTE.2018.2848923, IEEE Transactions on Sustainable Energy, (99), 1-1.

Ye, H, (2015). Control technology of wind turbine units. Beijing: China machine press.

Zhao, X. \& Mai, E. P. (2003). A novel power splitting drive train for variable speed wind power generators. Renewable Energy, 28(13), 2001-2011. https://doi.org/10.1016/S0960-1481(03)00127-7

Zhang, X.Y. (2014). Doubly Fed of Induction Generators Wind Turbine Frequency Control Based on Power Curve of Inertia Control and Pitch Angle Control. DOI: 10.4028/www.scientific.net/AMR.1070-1072.228. Advanced Materials Research, 456-475. https://doi.org/10.4028/www.scientific.net/AMR.1070-1072.228

\section{Copyrights}

Copyright for this article is retained by the author(s), with first publication rights granted to the journal.

This is an open-access article distributed under the terms and conditions of the Creative Commons Attribution license (http://creativecommons.org/licenses/by/4.0/). 